\title{
REPRESENTATIVENESS AND REPEATABILITY OF MICROENVIRONMENTAL PERSONAL AND HEAD EXPOSURES TO RADIO-FREQUENCY ELECTROMAGNETIC FIELDS
}

\author{
Arno Thielens ${ }^{a, b, *}$, Matthias Van den Bossche ${ }^{a}$, Christopher Brzozek ${ }^{c}$, Chhavi Raj Bhatt ${ }^{c}$, \\ Michael J. Abramson ${ }^{c}$, Geza Benke ${ }^{c}$, Luc Martens ${ }^{\mathrm{a}}$, Wout Joseph ${ }^{\mathrm{a}}$ \\ a Department of Information Technology, Ghent University/imec, Technologiepark- \\ Zwijnaarde 15, Ghent B-9052, Belgium \\ ${ }^{\mathrm{b}}$ Berkeley Wireless Research Center, Department of Electrical Engineering and Computer \\ Sciences, University of California, Berkeley, 2108 Allston Way, Suite 200, Berkeley, CA \\ 94704, United States of America \\ ${ }^{\mathrm{c}}$ Centre for Population Health Research on Electromagnetic Energy (PRESEE), School of \\ Public Health and Preventive Medicine, Monash University, 553 St Kilda Road, Victoria 3004, \\ Melbourne, Australia
}

Keywords: Radio-Frequency Electromagnetic Fields; Personal Exposure; Head Exposure

\begin{abstract}
The aims of this study were to: i) investigate the repeatability and representativeness of personal radio frequency-electromagnetic fields (RF-EMFs) exposure measurements, across different microenvironments, ii) perform simultaneous evaluations of personal RF-EMF exposures for the whole body and the head, iii) validate the data obtained with a head-worn personal distributed exposimeter (PDE) against those obtained with an on-body worn personal exposimeter (PEM). Data on personal and head RF-EMF exposures were collected by performing measurements across 15 microenvironments in Melbourne, Australia. A bodyworn PEM and a head-worn PDE were used for measuring body and head exposures, respectively. The summary statistics obtained for total RF-EMF exposure showed a high representativeness $\left(\mathrm{r}^{2}>0.66\right.$ for two paths in the same area) and a high repeatability over time $\left(\mathrm{r}^{2}>0.87\right.$ for repetitions of the same path). The median head exposure in the $900 \mathrm{MHz}$ downlink band ranged between $0.06 \mathrm{~V} / \mathrm{m}$ and $0.31 \mathrm{~V} / \mathrm{m}$. The results obtained during simultaneous measurements using the two devices showed high correlations $\left(0.42<\mathrm{r}^{2}<0.94\right)$. The highest mean total RF-EMF exposure was measured in Melbourne's central business district $(0.89 \mathrm{~V} / \mathrm{m})$, whereas the lowest mean total exposure was measured in a suburban residential area $(0.05 \mathrm{~V} / \mathrm{m})$. This study shows that personal RF-EMF microenvironmental measurements in multiple microenvironments have high representativeness and repeatability over time. The personal RF-EMF exposure levels (i.e. body and head exposures) demonstrated moderate to high correlations.
\end{abstract}

\section{Introduction}

Radiofrequency-electromagnetic fields (RF-EMFs) are omnipresent in our environment, as they enable wireless telecommunication. Consequently, most humans are constantly exposed to RF-EMFs and technologies that emit RF-EMFs such as mobile phones or mobile phone base stations. These RF-EMFs can have thermal effects (ICNIRP, 1998). 
Personal exposure to RF-EMFs can be measured using wearable devices, so-called personal exposimeters (PEMs) (Joseph et al., 2010; Bolte et al. 2016), which can register RF-EMFs over a wide range of frequencies $(0.1-6 \mathrm{GHz})$. These devices have previously been used systematically to investigate personal exposure in different microenvironments. A microenvironmental exposure assessment study usually consists of the following steps: Firstly, a set of predefined geographical areas is defined in which measurements will take place. Secondly, one path through the area is then commonly defined, and a trained researcher, wearing the PEM, follows those predefined paths for a number of times to evaluate personal exposure in that particular area/path (Bhatt et al. 2016a; Sagar et al., 2016; Urbinello et al., 2014a). This approach has the advantage that the researcher can control and preferentially eliminate self-induced RF-EMF exposure (exposure caused by the researcher's RF-EMF emitting devices), which causes measurement uncertainties (Röösli et al., 2010), and reduces inter-personal variability of the measurements (Neubauer et al., 2010).

There are four challenges associated with microenvironmental personal exposure measurements of RF-EMFs . Firstly, it is unclear whether repeated microenvironmental measurements of RF-EMFs yield reproducible results. Secondly, the representativeness of selected paths for the microenvironments in which they are defined has not been conclusively demonstrated. Previous findings (Beekhuizen et al. 2013; Sagar et al., 2016; Urbinello et al. 2014a) suggest that a path that requires at least $15 \mathrm{~min}$ of transportation time yields a reproducible arithmetic mean exposure measure. However, measured RF-EMF data can show a highly non-Gaussian distribution (Bhatt et al., 2016b), which implies that small (logarithmic) changes in the data could have a large effect on the arithmetic mean. Thirdly, there have been almost no studies that validate PEM measurements. Beekhuizen et al. (2013) used numerical simulations to compare PEM measurements and simulated RF-EMF fields. Thielens et al. (2016) used static measurements with a spectrum analyser and tri-axial antenna to compare with PEM measurements. However, both studies could not take temporal profiles of exposure into account. A successful approach for internal validation was used in Bhatt et al. (2016a), where two different types of PEMs were used simultaneously during the same microenvironmental measurements. Fourthly, measurements using PEMs are still confronted with relatively large measurement uncertainties up to a factor of one thousand (Bolte et al., 2016; Iskra et al., 2011). These are mainly caused by shielding of the body and detuning of the measurement device in the presence of the body (Bolte, 2016; Gajšek et al., 2015; Iskra et al., 2011; Neubauer et al., 2010; Thielens et al., 2015). The measurement uncertainties could be reduced by using an on-body calibration of the PEMs (Bolte, 2016; Bhatt et al., 2016b) and averaging over multiple devices on the body (Thielens et al., 2016). This led to the development of a personal distributed exposimeter (PDE) (Thielens et al., 2013), in the Global System for Mobile communications (GSM) $900 \mathrm{MHz}$ downlink (DL) band. This frequency band was chosen for prototyping, since it is one of the highest contributors to total DL exposure from mobile phone base stations (Bhatt et al., 2016a, 2016b; Sagar et al., 2016).

Recently, considerable research attention has been focused on potential cognitive effects of RF-EMF exposure (Abramson, et al., 2009; Kheifets et al., 2005; Roser et al., 2016; Bhatt et al., 2017), in particular associated with RF-EMF exposures to the head. In order to investigate 
such effects, there is a need to improve the assessment of head-specific personal exposure levels (van Deventer et al., 2011), both from near-field RF-EMF devices such as mobile phones and far-field RF-EMF devices such as mobile phone base stations. In order to measure RFEMF exposure to the head, we have installed the PDE into a helmet, so that it can measure head-specific RF-EMF exposure in the 900 DL band.

The goals of this study were to: i) perform (for the first time) simultaneous evaluation of the whole body (with PEMs) and the head (PDE-Helmet) RF-EMF exposures across various microenvironments, ii) evaluate representativeness and repeatability of personal microenvironmental RF-EMF exposure measurements, and iii) correlate and validate the concurrently measured RF-EMF exposures to the body and the head.

\section{Materials and methods}

\subsection{Study areas and design}

The study was conducted between $15^{\text {th }}$ November and $22^{\text {nd }}$ December 2016 in greater Melbourne, Australia, where 15 microenvironments (Röösli et al., 2010; Urbinello et al., 2014a, 2014b; Bhatt et al., 2016a) were defined. The characteristics of each microenvironment, its spatial characteristics, and the activities undertaken therein by the subjects (researchers AT, $\mathrm{CB}$ and $\mathrm{CRB}$ ) while performing personal body and head exposure measurements are summarized in Table 1 in Appendix A.

The studied microenvironments (see Table 1 in appendix A) have been selected to cover different (sub-)urban activities in the greater Melbourne area: residential areas (9, 11-15), industrial areas (area 7), areas dedicated to trade, commerce and tourism (3, 5, and 6), recreational areas (areas 1-3, and 8), and college/university areas (4 and 10). Another aim was to cover different population densities in the greater Melbourne area. The studied microenvironments covered population densities from 250 inhabitants $/ \mathrm{km}^{2}$ up to 15000 inhabitants $/ \mathrm{km}^{2}$. This resulted in a total of 15 studied microenvironments.

In each microenvironment, two paths of similar length (max $\pm 20 \%$ deviation) were predefined. In every microenvironment, one out of three different modes of transportation was used to follow the paths: walking, driving a car, and riding a bicycle. The paths were defined in such a way that it took at least 15 minutes to follow them, in line with the recommendations of Beekhuizen et al. (2013), Sagar et al. (2016), and Urbinello et al. (2014a). These paths were followed at three different timeslots during the day: morning (9am - 12noon), midday (12noon $-3 \mathrm{pm})$, and afternoon ( $3 \mathrm{pm}-6 \mathrm{pm})$. Measurements were only conducted on weekdays - from Monday to Friday. Each path was repeated five times, once on each day of the week, and was executed twice in two different timeslots and once in the remaining third timeslot. Of the five repetitions, two were executed in such a way that two researchers followed the two paths in the same microenvironment simultaneously. This resulted in $15 \times 2 \times 5=150$ measurements along predefined paths. In addition to these microenvironmental measurements, measurements were also conducted in seven places of interest, which were six train and subway stations and in the outskirts of one public playground. Measurements were also performed during transportation between the different paths. During these measurements, the following modes of transportation 
were used: car, bike, train, tram, metro and walking (see Appendix A). The difference between the 15 studied microenvironments and the places of interest was that the researchers had to follow predefined paths only in the microenvironments, while they were free to move around in the places of interest. The type and route of transportation in between the microenvironments was also not predefined.

Two types of measurements were conducted: Firstly, one researcher followed one of the predefined paths while wearing two PEMs and the PDE-Helmet if the researcher was riding a bike (areas 1, 2 and 9). Secondly, two researchers followed the two paths in one area simultaneously, each wearing one PEM. One of the researchers wore the PDE-Helmet if the paths were followed while riding a bicycle.

During the measurements, GPS coordinates were collected by two PEMs that were worn on the body of the researcher(s). The researchers' wireless devices such as mobile phones were in flight mode, eliminating any contribution to RF-EMF exposure.

\subsection{Measurement Devices}

\subsubsection{The ExpoM-RF}

The ExpoM-RF is a PEM developed by Fields At Work (http://www.fieldsatwork.ch), which measures electric field strengths on the body $\left(E_{b o d y}\right)$ in 16 different frequency bands every $4 \mathrm{~s}$. Figure 1 (a) shows an illustration of the ExpoM-RF. Table I lists the frequency bands and the detection ranges of the Expom-RF in those bands. The ExpoM-RF was not calibrated on the body of the subject in this study, since we were interested in comparing our results to other studies where such a calibration was not usually conducted.

Table 1: Overview of the frequency bands and the sensitivity range (lower and upper limit of detection (LOD)) of the RF-EXPOM. UL stands for uplink, while DL stands for DL (Fields at work, 2017). The right column lists the percentage of non-detects in each frequency band.

\begin{tabular}{lccc}
\hline Service & $\begin{array}{c}\text { Frequency range } \\
\text { (MHz) }\end{array}$ & $\begin{array}{c}\text { Sensitivity range: } \\
\text { Lower LOD - } \\
\text { upper LOD (V/m) }\end{array}$ & $\begin{array}{c}\text { Percentage of } \\
\text { Measurements } \\
\text { underneath lower } \\
\text { LOD (\%) }\end{array}$ \\
\hline FM Radio & $87.5-108$ & $0.02-5$ & 74 \\
DVB-T & $470-790$ & $0.005-5$ & 19 \\
800 DL & $791-821$ & $0.005-5$ & 39 \\
800 UL & $832-862$ & $0.005-5$ & 37 \\
900 UL & $880-915$ & $0.005-5$ & 7.2 \\
900 DL & $925-960$ & $0.005-5$ & 0.2 \\
1800 UL & $1710-1785$ & $0.005-5$ & 74 \\
1800 DL & $1805-1880$ & $0.005-5$ & 6 \\
DECT & $1880-1900$ & $0.005-5$ & 29 \\
2100 UL & $1920-1980$ & $0.003-5$ & 89 \\
2100 DL & $2110-2170$ & $0.003-5$ & 11 \\
WiFi 2G & $2400-2485$ & $0.005-5$ & 16 \\
2600 UL & $2500-2570$ & $0.003-5$ & 92 \\
2600 DL & $2620-2690$ & $0.003-5$ & 94 \\
WiMax 3.5 & $3400-3600$ & $0.003-3$ & 81 \\
WiFi-5G & $5150-5875$ & $0.05-5$ & \\
\hline
\end{tabular}




\subsubsection{The PDE-Helmet}

The PDE-Helmet is a measurement device developed at Ghent University (Thielens et al., 2016). It uses multiple RF nodes that are distributed over the head, in order to reduce the measurement uncertainty on the incident RF power density. The device measures incident electric fields on the head of a subject ( $E_{h e a d}$ ) with a frequency of $1 \mathrm{~Hz}$ in the GSM $900 \mathrm{DL}$ band (920-960 MHz). The detection range of the PDE-Helmet (with on-body calibration) was $11.3 \mathrm{mV} / \mathrm{m}-113 \mathrm{~V} / \mathrm{m}$. A previous prototype of the device, which consisted of body-worn textile antennas, has been used successfully (Thielens et al., 2016; Bhatt et al., 2016a). The current prototype was designed for measurements during bicycle rides and uses folded stub antennas, see Fig. 1, integrated in a bicycle helmet. The ensemble of four stub antennas formed a (quasi-) isotropic antenna. Appendix B contains details of the on-body (on-head) calibration of the PDE- Helmet.

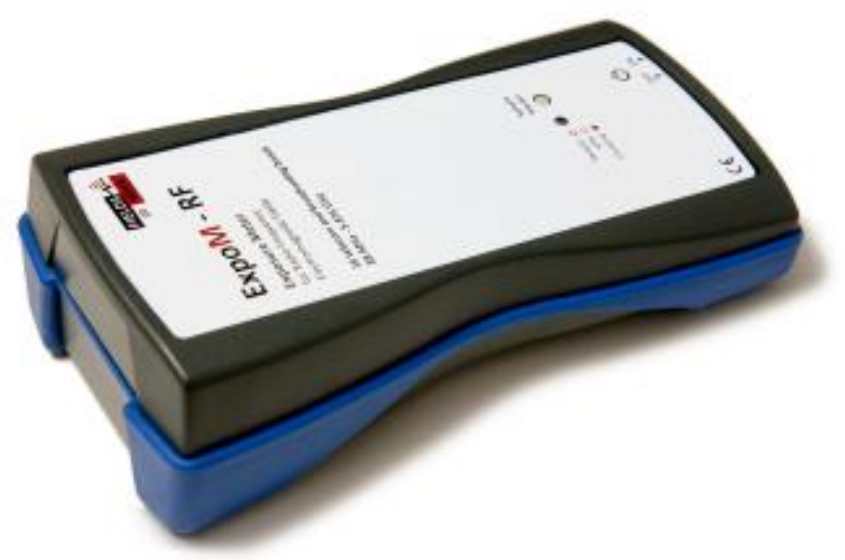

(a) 

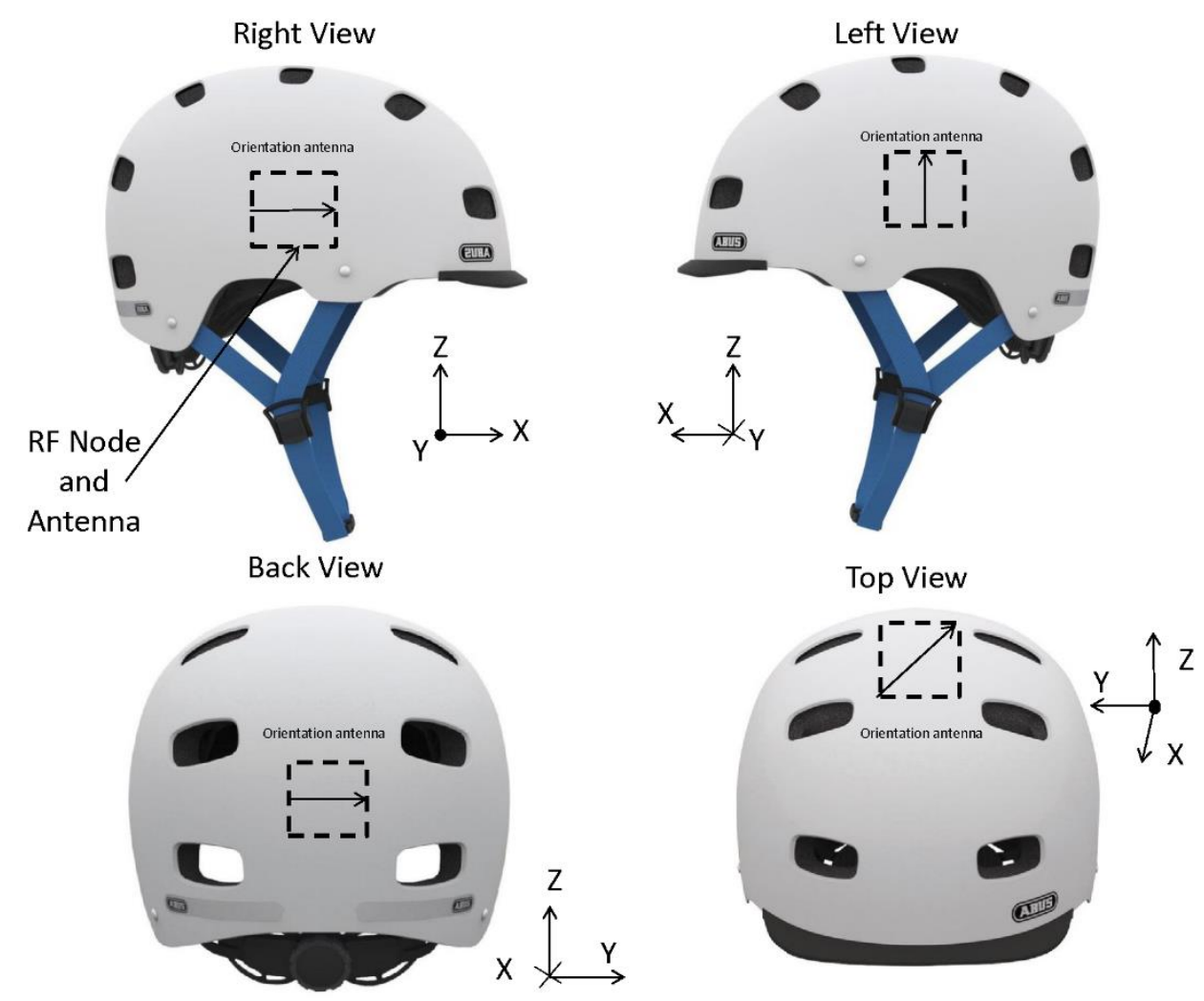

(b)

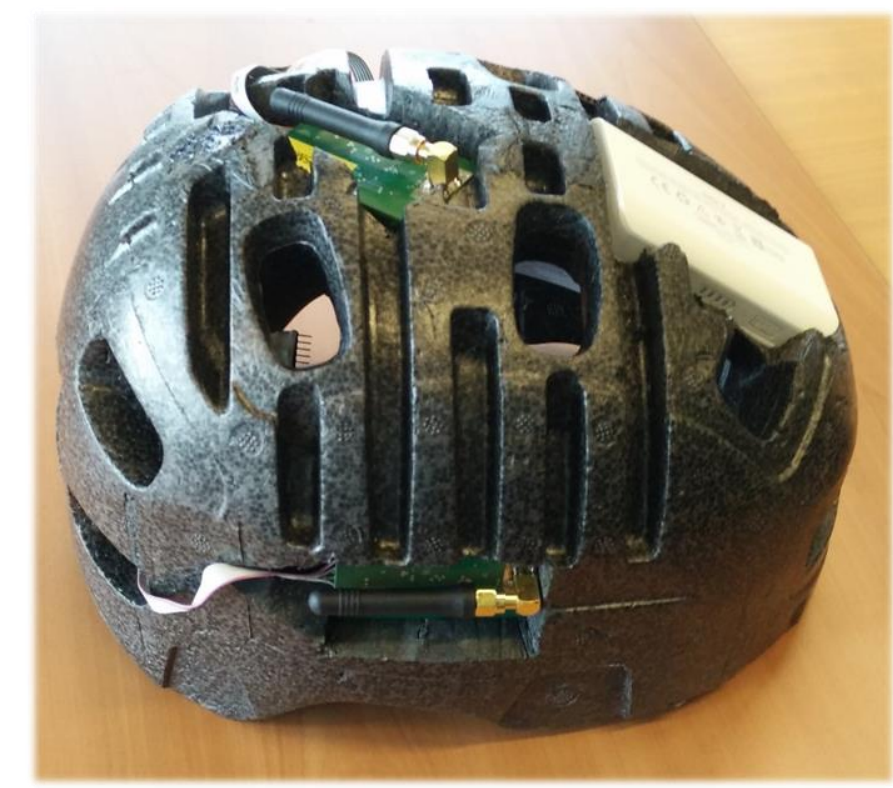

(c)

Figure 1. The used measurement devices: (a) the ExpoM-RF (image source: Fields at work, 2017), (b) outside view of the PDE-Helmet with locations of the antennas inside the helmet, and $(c)$ interior of the helmet showing the padding in black, the folded stub antennas with receiver nodes in green-black-gold, and the battery in white.

\subsection{Data processing and Statistical analysis}


The ExpoM-RF devices provided electric field strength values (E) in the different RF-EMF frequency bands listed in Table 1, while the PDE-Helmet provided E field values in the 900 DL band. The values falling below the lower limit of detection (LOD) were replaced by LOD $/ \sqrt{2}$ (Ganser and Hewett, 2010). There were no data higher than the upper limit of detection. The devices registered all instances in which this substitution took place in each frequency band listed in Table 1 (right column).

All $E$ values were translated to power density $\left(S_{\text {inc }}\right)$ values using: $S_{\text {inc }}=E^{2} / 377$, in each frequency band. During measurements where two ExpoM-RF devices were used simultaneously by the same researcher, geometric means of $S_{\text {inc }}$ obtained with the two ExpoMRFs were computed using the formula: Geometric mean $=\left(S_{\mathrm{inc}, 1} \times S_{\mathrm{inc}, 2}\right)^{1 / 2}$, since this reduced the measurement uncertainty on the mean (Thielens et al., 2015; Bhatt et al., 2016b).

The power densities were further processed to determine the following quantities:

i. Total exposure: This was the sum of all measured power densities in each frequency band at each time instance.

ii. Total Telecommunication Downlink exposure: This was the sum of all measured power densities on each time instance in telecommunication downlink (DL) signals: 800 DL, 900 DL, 1800 DL, 2100 DL, and 2600 DL.

iii. Total Telecommunication Uplink exposure: This was the sum of all measured power densities on each time instance in telecommunication up (UL) signals: 800 UL, 900 UL, 1800 UL, 2100 UL, and 2600 UL.

iv. Total Broadcast exposure: This was the sum of all measured power densities on each time instance in bands used for broadcasting: FM and DVBT

v. Total other exposure: This was the sum of all measured power densities in the remaining bands: DECT, Wi-Fi 2G, and Wi-Fi $5 \mathrm{G}$.

vi. GSM 900 DL exposure: These were the measured power densities in the GSM 900 DL band.

For each of these quantities, we calculated the $16^{\text {th }}, 50^{\text {th }}, 84^{\text {th }}$ and $95^{\text {th }}$ percentiles, the arithmetic average, and the geometric average along each path. The same statistics were calculated for the measurements in the GSM 900 DL band that were executed using the PDE-Helmet.

In order to provide descriptive statistics for the personal exposures, we also calculated these statistics on the pooled data for both paths and all repetitions in each microenvironment. The relative contributions of the DL, UL, Broadcast, and other exposure, to the total exposure in each microenvironment were calculated as well.

The same summary statistics were also defined for each time of day, pooled for all paths, modes of transportation, and microenvironments that were executed in those three time slots: morning (9am - 12noon), midday (12noon - 3pm), and afternoon (3pm-6pm). The one-tailed Wilcoxon rank sum (WRS) test was performed to compare exposure levels across the time slot groups (i.e. morning-midday, morning-afternoon, midday-afternoon, and afternoon-midday).

In order to investigate the representativeness, we performed two analyses: i) firstly, we investigated Spearman correlations between the summary statistics obtained from both paths 
in the same microenvironment (number of environments $=15$ ), both for simultaneous measurements and non-simultaneous measurements; ii) secondly, we also used the two-tailed WRS test to determine whether samples measured along each of the two paths in the same environment could come from the same distribution. This analysis was split for simultaneous (13 microenvironments $\times 2$ simultaneous measurements) and non-simultaneous measurements (13 microenvironments $\times 3$ non-simultaneous measurements and 2 microenvironments $\times 5$ nonsimultaneous measurements), with the goal of determining whether better representativeness could be obtained for the simultaneous measurements.

In order to investigate the repeatability, we first performed pairwise Spearman correlations between the summary statistics obtained from the five repetitions of the individual paths in the same microenvironment. All five repetitions were combined with the other four repetitions of the same paths. However, this would lead to an enormous set of combinations. We have therefore chosen to work with a stochastic approach, where 100 randomly chosen sets of 2 repetitions per path (2) per microenvironment (15) were used to determine statistics of the correlation coefficients.

In order to compare measurement results obtained with different measurement devices, namely the PDE-Helmet and the (pair of) ExpoM-RF(s), we compared correlations of the summary statistics obtained with different measurement devices obtained during simultaneous use of both devices. We compared the summary statistics obtained using two simultaneously worn ExpoM-RF devices and those obtained from the PDE-Helmet with those obtained using (a pair of) simultaneously worn ExpoM-RF(s). Since the PDE-Helmet was calibrated on the body and the ExpoM-RFs were calibrated in a free-space, which lead to an offset in measurement results due to body shielding (Thielens et al., 2015; Bhatt et al., 2016b), we did not expect to find acceptance of the null hypothesis of a WRS test. However, we have executed the test as a verification.

For all WRS tests, $\mathrm{p}<0.05$ was considered as statistically significant. All post-processing of the measurement data was carried out using MATLAB R2016a (The MathWorks Inc, Natick, Massachusetts, USA).

All the processing was performed using RF-EMF power densities $\left(\mathrm{S}_{\mathrm{inc}}\right.$ in $\left.\mathrm{W} / \mathrm{m}^{2}\right)$, since this is the quantity which is measured by the detectors in the measurement devices (Bolte, 2016). We have chosen to report Electric field strength values $(\mathrm{E}$ in $\mathrm{V} / \mathrm{m})$ in the results section, since this is the quantity which is most commonly reported in literature (Bhatt et al., 2016a,b; Bolte and Eikelboom, 2012; Urbinello et al., 2014a,b,c). Both quantities are related through: $E=\sqrt{377 \times S_{\text {inc }}}$

\section{Results}

We obtained RF-EMF exposure levels in 15 microenvironments and six places of interest in Melbourne, Australia. These showed a dependency on the time of day. Summary statistics of RF-EMF exposure measured along different paths in the same microenvironments correlate very well, so do those obtained using different measurement devices. 


\subsection{Descriptive statistics}

Proportions of non-detects range from $0.2 \%$ (900 DL) up to $94 \%$ (WiMax $3.5 \mathrm{GHz}$ ). Table 1 and Table C.1 in Appendix C list the proportions of non-detects, which are all values falling below the LODs of the ExpoM-RFs. The percentages are calculated taking into account all measured data that were used to calculate summary statistics (shown in Fig. 2 and Table 2).

The area with the highest 'Total' average exposure $(0.89 \pm 1.07 \mathrm{~V} / \mathrm{m})$ was CBD 1: the riverside area in Melbourne's central business district (CBD). Table 2 shows the summary statistics per microenvironment in terms of 'DL', 'UL' 'Broadcast' "Others' and 'Total' RF-EMF exposures measured with ExpoM-RFs. The other areas in the CBD: CBD $2(0.79 \pm 0.89 \mathrm{~V} / \mathrm{m})$ and CBD 3 $(0.72 \pm 0.88 \mathrm{~V} / \mathrm{m})$, ranked $2^{\text {nd }}$ and $3^{\text {rd }}$ in highest 'Total' average exposure. The lowest average 'Total' average exposure was measured in the less populated (see Table A.1 in Appendix A) suburban and industrial areas in Werribee and Altona, respectively: the industrial area $(0.09 \pm 0.1 \mathrm{~V} / \mathrm{m})$, suburban area $4(0.05 \pm 0.04 \mathrm{~V} / \mathrm{m})$, suburban area $5(0.06 \pm 0.06 \mathrm{~V} / \mathrm{m})$, and suburban area $6(0.12 \pm 0.2 \mathrm{~V} / \mathrm{m})$. Most of the 'Total' RF-EMF exposure was attributed to DL RF-EMF signals. In all areas except the industrial area and suburban area 4, the DL RF-EMF signal was the dominant source of RF-EMF exposure. The second largest contributors to 'Total' RF-EMF exposure were either UL from other users or other signals, also emitted by other users. 'Broadcast' exposure was always the lowest contributor to the 'Total' exposure, except in CBD 3 ('Others') and suburban area 4 ('DL' and 'UL'). 
Table 2. Summary statistics of $E_{r m s}$ using the ExpoM-RFs in 15 microenvironments, 6 modes of transport, and 6 places of interest in Melbourne.

\begin{tabular}{|c|c|c|c|c|c|c|c|c|c|c|c|c|c|c|c|c|c|c|c|c|c|c|c|c|c|c|c|c|c|c|}
\hline \multirow[t]{2}{*}{$\mathbf{E}_{\text {rms }}(\mathbf{V} / \mathbf{m})$} & \multicolumn{6}{|c|}{ DL } & \multicolumn{6}{|c|}{$\mathbf{U L}$} & \multicolumn{6}{|c|}{ Broadcast } & \multicolumn{6}{|c|}{ Others } & \multicolumn{6}{|c|}{ Total } \\
\hline & $\mu^{\mathrm{a}}$ & std & $p_{16}$ & $p_{50}$ & $p_{84}$ & $p_{95}$ & $\mu$ & std & $p_{16}$ & $p_{50}$ & $p_{84}$ & $p_{95}$ & $\mu$ & std & $p_{16}$ & $p_{50}$ & $p_{84}$ & $p_{95}$ & $\mu$ & std & $p_{16}$ & $p_{50}$ & $p_{84}$ & $p_{95}$ & $\mu$ & std & $p_{16}$ & $p_{50}$ & $p_{84}$ & $p_{95}$ \\
\hline \multicolumn{31}{|l|}{ Microenvironment } \\
\hline 1, park close to CBD 1 & 0.34 & 0.47 & 0.07 & 0.18 & 0.47 & 0.74 & 0.15 & 0.25 & 0.03 & 0.07 & 0.16 & 0.34 & 0.06 & 0.07 & 0.03 & 0.05 & 0.08 & 0.11 & 0.07 & 0.11 & 0.02 & 0.04 & 0.08 & 0.15 & 0.39 & 0.51 & 0.09 & 0.22 & 0.53 & 0.83 \\
\hline 2, park close to CBD 2 & 0.47 & 0.69 & 0.15 & 0.29 & 0.58 & 0.95 & 0.20 & 0.34 & 0.06 & 0.12 & 0.22 & 0.40 & 0.07 & 0.13 & 0.03 & 0.05 & 0.08 & 0.13 & 0.10 & 0.17 & 0.03 & 0.05 & 0.10 & 0.19 & 0.53 & 0.75 & 0.17 & 0.34 & 0.66 & 1.03 \\
\hline 3 , CBD 1 & 0.79 & 0.98 & 0.29 & 0.55 & 1.04 & 1.50 & 0.33 & 0.39 & 0.12 & 0.23 & 0.43 & 0.62 & 0.15 & 0.22 & 0.05 & 0.09 & 0.19 & 0.29 & 0.19 & 0.27 & 0.06 & 0.11 & 0.24 & 0.38 & 0.89 & 1.07 & 0.36 & 0.64 & 1.17 & 1.66 \\
\hline 4, University Campus 1 & 0.53 & 0.8 & 0.08 & 0.24 & 0.67 & 1.13 & 0.16 & 0.22 & 0.04 & 0.09 & 0.21 & 0.32 & 0.10 & 0.2 & 0.03 & 0.05 & 0.10 & 0.19 & 0.12 & 0.23 & 0.03 & 0.05 & 0.13 & 0.25 & 0.57 & 0.86 & & 0.27 & 0.74 & 1.22 \\
\hline 5, CBD 2 & 0.70 & 0.82 & 0.27 & 0.50 & 0.91 & 1.34 & 0.28 & 0.4 & 0.08 & 0.17 & 0.35 & 0.54 & 0.17 & 0.2 & 0.07 & 0.11 & 0.22 & 0.33 & 0.18 & 0.24 & 0.07 & 0.12 & 0.22 & 0.35 & 0.79 & 0.89 & 0.34 & 0.60 & 1.05 & 1.46 \\
\hline 6, CBD 3 & 0.65 & 0.83 & 0.26 & 0.46 & 0.82 & 1.22 & 0.24 & 0.33 & 0.08 & 0.16 & 0.30 & 0.45 & 0.15 & 0.21 & 0.07 & 0.11 & 0.19 & 0.28 & 0.14 & 0.2 & 0.06 & 0.10 & 0.17 & 0.28 & 0.72 & 0.88 & 0.31 & 0.53 & 0.93 & 1.36 \\
\hline 7, Industrial Area & 0.05 & 0.09 & 0.02 & 0.02 & 0.06 & 0.11 & 0.02 & 0.04 & 0.01 & 0.01 & 0.03 & 0.06 & 0.02 & 0.01 & 0.02 & 0.02 & 0.02 & 0.02 & 0.06 & 0.05 & 0.04 & 0.06 & 0.09 & 0.10 & 0.09 & 0.1 & 0.06 & 0.08 & 0.11 & 0.15 \\
\hline & 0.19 & 0.24 & 0.07 & 0.12 & 0.24 & 0.40 & 0.05 & 0.07 & 0.02 & 0.04 & 0.07 & 0.10 & 0.03 & 0.03 & 0.02 & 0.02 & 0.04 & 0.05 & 0.04 & 0.05 & 0.02 & 0.03 & 0.05 & 0.08 & 0.21 & 0.25 & & 0.14 & 0.26 & 0.42 \\
\hline 9, Suburban Area 1 & 0.33 & 0.59 & 0.03 & 0.07 & 0.34 & 0.78 & 0.11 & 0.22 & 0.01 & 0.04 & 0.13 & 0.23 & 0.05 & 0.08 & 0.02 & 0.04 & 0.04 & 0.08 & 0.07 & 0.14 & 0.02 & 0.04 & 0.07 & 0.14 & 0.36 & 0.62 & 0.04 & 0.09 & 0.39 & 0.83 \\
\hline 10, University Campus 2 & 0.41 & 0.61 & 0.11 & 0.25 & 0.50 & 0.76 & 0.11 & 0.15 & 0.04 & 0.07 & 0.14 & 0.22 & 0.06 & 0.1 & 0.03 & 0.04 & 0.07 & 0.11 & 0.09 & 0.13 & 0.03 & 0.06 & 0.10 & 0.16 & 0.43 & 0.64 & 0.13 & 0.27 & 0.54 & 0.81 \\
\hline 11 , Suburba & 0.21 & 0.44 & 0.02 & 0.04 & 0.14 & 0.43 & 0.05 & 0.09 & 0.02 & 0.02 & 0.05 & 0.11 & 0.03 & 0.07 & 0.01 & 0.02 & 0.03 & 0.06 & 0.06 & 0.15 & 0.01 & 0.02 & 0.04 & 0.10 & 0.23 & 0.47 & 0.04 & 0.06 & 0.16 & 0.47 \\
\hline 12, Suburb & 0.23 & 0.39 & 0.04 & 0.11 & 0.27 & 0.48 & 0.07 & 0.15 & 0.02 & 0.03 & 0.07 & 0.13 & 0.03 & 0.05 & 0.01 & 0.02 & 0.03 & 0.06 & 0.05 & 0.09 & 0.02 & & & 0.09 & 0.25 & 0.41 & & & 0.28 & 0.52 \\
\hline 13, Suburban Area 4 & 0.02 & 0.02 & 0.01 & 0.02 & 0.03 & 0.04 & 0.02 & 0.02 & 0.01 & 0.01 & 0.02 & 0.03 & 0.03 & 0.02 & 0.01 & 0.02 & 0.04 & 0.04 & 0.03 & 0.02 & 0.01 & 0.02 & 0.04 & 0.04 & 0.05 & 0.04 & 0.03 & 0.05 & 0.06 & 0.07 \\
\hline 14, Suburban Area 5 & 0.05 & 0.05 & 0.03 & 0.04 & 0.06 & 0.09 & 0.02 & 0.03 & 0.01 & 0.02 & 0.02 & 0.03 & 0.02 & 0.02 & 0.01 & 0.02 & 0.04 & 0.04 & 0.03 & 0.02 & 0.01 & 0.02 & 0.04 & 0.04 & 0.06 & 0.06 & 0.04 & 0.06 & 0.08 & 0.10 \\
\hline 15, Suburban Area 6 & 0.10 & 0.18 & 0.01 & 0.02 & 0.13 & 0.22 & 0.03 & 0.05 & 0.01 & 0.01 & 0.04 & 0.07 & 0.03 & 0.03 & 0.02 & 0.02 & 0.04 & 0.04 & 0.05 & 0.09 & 0.02 & 0.02 & 0.04 & 0.08 & 0.12 & 0.2 & 0.03 & 0.05 & 0.15 & 0.26 \\
\hline \multicolumn{31}{|l|}{ Mode of Transport } \\
\hline Train & 0.17 & 0.33 & 0.03 & 0.06 & 0.16 & 0.33 & 0.13 & 0.27 & 0.03 & 0.06 & 0.15 & 0.26 & 0.05 & 0.08 & 0.02 & 0.03 & 0.05 & 0.09 & 0.06 & 0.09 & 0.03 & 0.04 & 0.07 & 0.11 & 0.23 & 0.39 & 0.08 & 0.12 & 0.26 & 0.45 \\
\hline Bus & 0.10 & 0.16 & 0.03 & 0.05 & 0.11 & 0.25 & 0.07 & 0.11 & 0.03 & 0.04 & 0.08 & 0.13 & 0.03 & 0.04 & 0.02 & 0.02 & 0.04 & 0.08 & 0.04 & 0.04 & 0.02 & 0.03 & 0.05 & 0.07 & 0.14 & 0.17 & 0.06 & 0.09 & 0.17 & 0.29 \\
\hline Tram & 0.34 & 0.62 & 0.05 & 0.15 & 0.36 & 0.65 & 0.11 & 0.20 & 0.03 & 0.06 & 0.13 & 0.22 & 0.11 & 0.21 & 0.03 & 0.05 & 0.11 & 0.22 & 0.09 & 0.16 & 0.03 & 0.05 & 0.09 & 0.16 & 0.38 & 0.66 & 0.10 & 0.20 & 0.42 & 0.72 \\
\hline Bike & 0.48 & 0.69 & 0.12 & 0.31 & 0.60 & 0.94 & 0.19 & 0.32 & 0.04 & 0.10 & 0.21 & 0.37 & 0.08 & 0.14 & 0.03 & 0.05 & 0.08 & 0.14 & 0.10 & 0.17 & 0.03 & 0.06 & 0.11 & 0.19 & 0.53 & 0.74 & 0.14 & 0.36 & 0.67 & 1.02 \\
\hline $\mathrm{Car}$ & 0.15 & 0.24 & 0.02 & 0.06 & 0.18 & 0.31 & 0.07 & 0.14 & 0.01 & 0.02 & 0.07 & 0.14 & 0.03 & 0.03 & 0.02 & 0.03 & 0.04 & 0.05 & 0.07 & 0.07 & 0.03 & 0.06 & 0.09 & 0.10 & 0.18 & 0.27 & 0.06 & 0.11 & 0.21 & 0.36 \\
\hline Walking & 0.61 & 1 & 0.05 & 0.31 & 0.74 & 1.23 & 0.19 & 0.30 & 0.03 & 0.11 & 0.23 & 0.39 & 0.19 & 0.47 & 0.02 & 0.05 & 0.15 & 0.32 & 0.14 & 0.25 & 0.03 & 0.07 & 0.16 & 0.30 & 0.69 & 1.07 & 0.08 & 0.37 & 0.85 & 1.43 \\
\hline \multicolumn{31}{|l|}{ Places of interest } \\
\hline Melbourne Central & 0.30 & 0.35 & 0.06 & 0.21 & 0.46 & 0.54 & 0.16 & 0.18 & 0.04 & 0.10 & 0.26 & 0.30 & 0.12 & 0.14 & 0.06 & 0.09 & 0.15 & 0.19 & 0.14 & 0.22 & 0.09 & 0.11 & 0.15 & 0.19 & 0.39 & 0.37 & 0.14 & 0.37 & 0.51 & 0.60 \\
\hline Prahran Station & 0.08 & 0.07 & 0.06 & 0.07 & 0.09 & 0.11 & 0.04 & 0.03 & 0.03 & 0.03 & 0.04 & 0.05 & 0.03 & 0.03 & 0.01 & 0.04 & 0.04 & 0.04 & 0.04 & 0.03 & 0.02 & 0.04 & 0.04 & 0.05 & 0.10 & 0.07 & 0.08 & 0.10 & 0.11 & 0.13 \\
\hline Flinders St. & 0.49 & 0.82 & 0.14 & 0.24 & 0.45 & 1.14 & 0.14 & 0.37 & 0.04 & 0.05 & 0.11 & 0.24 & 0.10 & 0.19 & 0.04 & 0.05 & 0.08 & 0.23 & 0.16 & 0.21 & 0.08 & 0.12 & 0.18 & 0.29 & 0.54 & 0.88 & 0.20 & 0.29 & 0.50 & 1.24 \\
\hline Glenferrie & 0.24 & 0.26 & 0.10 & 0.17 & 0.33 & 0.37 & 0.08 & 0.11 & 0.04 & 0.07 & 0.10 & 0.13 & 0.04 & 0.07 & 0.02 & 0.03 & 0.04 & 0.05 & 0.05 & 0.07 & 0.03 & 0.04 & 0.05 & 0.06 & 0.26 & 0.27 & 0.12 & 0.19 & 0.35 & 0.40 \\
\hline North Melb. Station & 0.11 & 0.13 & 0.05 & 0.07 & 0.13 & 0.23 & 0.16 & 0.28 & 0.06 & 0.08 & 0.13 & 0.34 & 0.04 & 0.05 & 0.02 & 0.02 & 0.05 & 0.08 & 0.06 & 0.07 & 0.03 & 0.04 & 0.08 & 0.12 & 0.21 & 0.29 & 0.10 & 0.13 & 0.29 & 0.36 \\
\hline Playground & 0.33 & 0.3 & 0.19 & 0.27 & 0.47 & 0.53 & 0.18 & 0.16 & 0.10 & 0.14 & 0.24 & 0.27 & 0.06 & 0.05 & 0.04 & 0.05 & 0.08 & 0.09 & 0.08 & 0.08 & 0.04 & 0.06 & 0.12 & 0.13 & 0.39 & 0.35 & 0.22 & 0.32 & 0.56 & 0.62 \\
\hline
\end{tabular}


Walking $(0.69 \pm 1.07 \mathrm{~V} / \mathrm{m})$ and riding a bicycle $(0.53 \pm 0.74 \mathrm{~V} / \mathrm{m})$ lead to the higher average 'Total' exposure in comparison to the other modes of transportation. However, most of walking and bicycle riding took place between microenvironments in or near the CBD. Surprisingly, the UL was also found to be higher on average while walking or riding a bicycle, than while taking public transport. DL was dominant during most of the modes of transportation. On the train, UL was comparable to DL. Those places of interest which showed the highest average exposure were Flinders Street $(0.54 \pm 0.88 \mathrm{~V} / \mathrm{m})$, Melbourne Central $(0.39 \pm 0.37 \mathrm{~V} / \mathrm{m})$, and the playground $(0.39 \pm 0.35 \mathrm{~V} / \mathrm{m})$. These are located near the CBD.

Figure 2 shows the $\mathrm{E}_{\mathrm{rms}}$ measured using the ExpoM-RF devices per microenvironment, with the relative contribution of each to the studied exposure quantities. Figure 2 also shows the same results for the studied places of interest and the modes of transportation in between microenvironments.

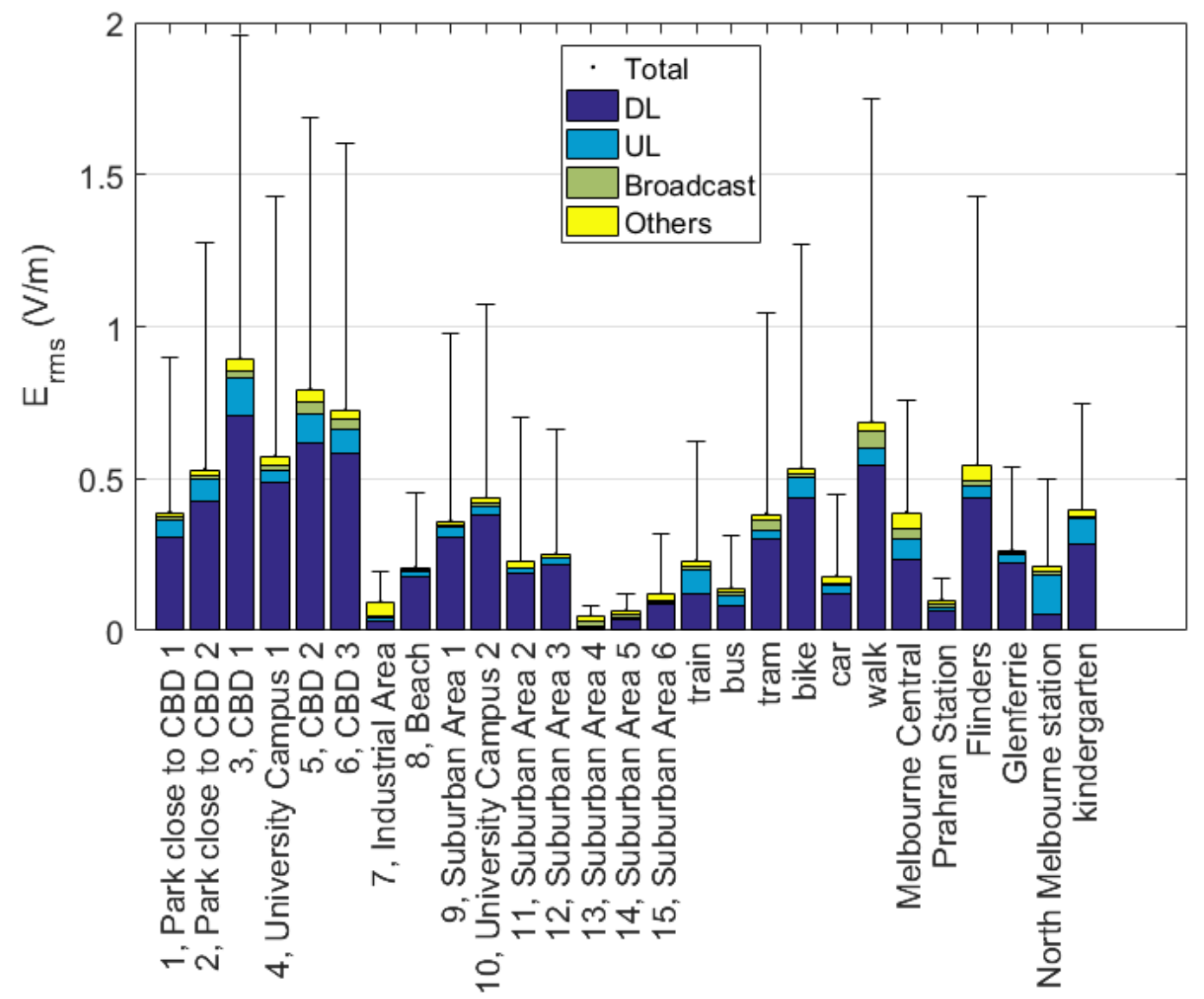

Figure 2: Arithmetic average measured $E_{r m s}$ in all frequency bands in the 15 microenvironments listed in Table A.1 in Melbourne, Australia. The height of the bars indicate the total average $E_{r m s}$, while the different subdivisions of the bars indicate the relative contributions of DL, UL, Broadcast, and Other RF-EMF signals to Total Exposures.

The whiskers indicate the standard deviation on the arithmetic mean. 
Figure 3 shows the average total $\mathrm{E}_{\mathrm{rms}}$ for the three considered times of day: morning (9am 12 noon), midday (12noon- $3 \mathrm{pm})$, and evening $(3 \mathrm{pm}-6 \mathrm{pm})$. These average values were obtained using one repetition of each path in each of the three time categories. We could not use all five repetitions here, because this might introduce bias (for example environments with higher exposure could have been executed more often in the morning).

For 'DL', 'UL', 'Others' and 'Total' exposure groups, we found significantly higher median exposure levels in the midday compared to those in the morning $(\mathrm{p}<0.01)$. Whereas, for 'Broadcast' exposure level, there was no statistically significant difference between median midday and morning exposure levels $(\mathrm{p}=0.39)$. Similarly, for 'DL', 'Other' and 'Total' exposure groups, the median exposure levels in the morning were significantly lower compared to those in the afternoon ( $p<0.01)$. Whereas, for 'UL' $(p=0.08)$ and 'Broadcast' $(p=0.99)$ exposure groups, there was no statistically significant difference between median afternoon and morning exposure levels. The 'Others' exposure group was found to show a statistically higher median exposure level $(\mathrm{p}<0.01)$ in the afternoon in comparison to midday, while ' $\mathrm{DL}$ ' $(\mathrm{p}=0.02)$, 'UL' $(\mathrm{p}<0.01)$, and 'Total' $(\mathrm{p}<0.01)$ exposure showed a higher median exposure level at midday in comparison to the afternoon. We did not find a significant difference $(\mathrm{p}=$ 0.08) for 'Broadcast' between afternoon and midday.

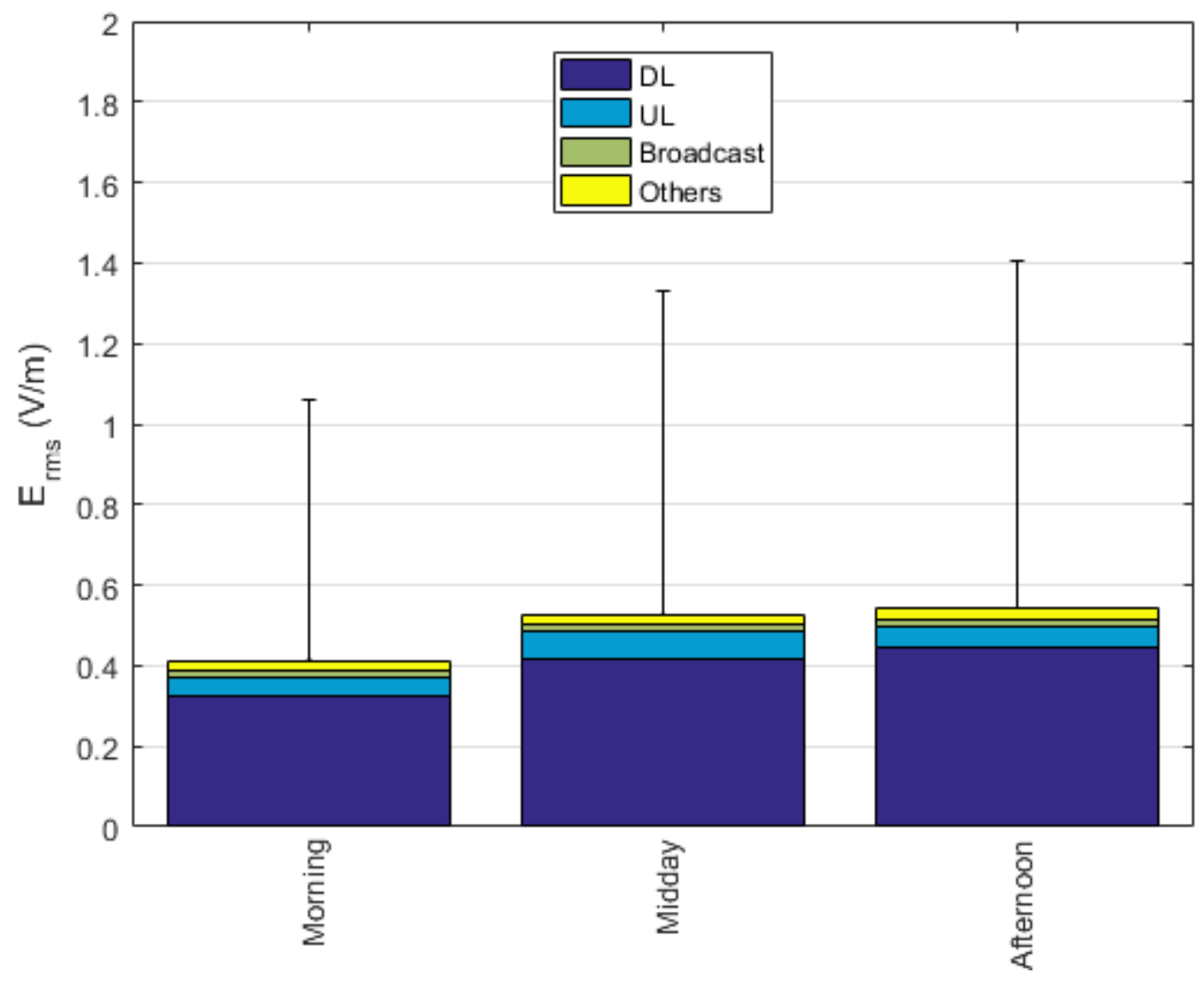

Figure 3: Arithmetic average measured $E_{\text {rms }}$ in all frequency bands in the 3 time-slots considered in Melbourne, Australia. The height of the bars indicate the total average $E_{r m s,}$ while the different subdivisions of the bars indicate the relative contributions of $D L, U L$, 
Broadcast, and Other signals. The whiskers indicate the standard deviation on the arithmetic mean.

\subsection{Representativeness of Summary Statistics}

Figure 4 shows scatterplots of the percentiles of the total exposure measured along two paths in the same area. We generally find high correlations $\left(r^{2}>0.8\right)$ between percentiles for the total $\mathrm{E}_{\mathrm{rms}}$ determined along two paths in the same environment, when all five repetitions of the same path were pooled in one dataset.

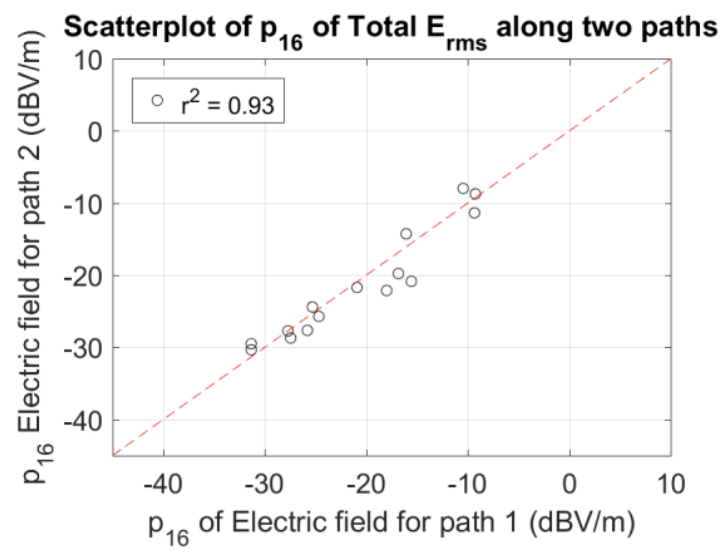

(a)

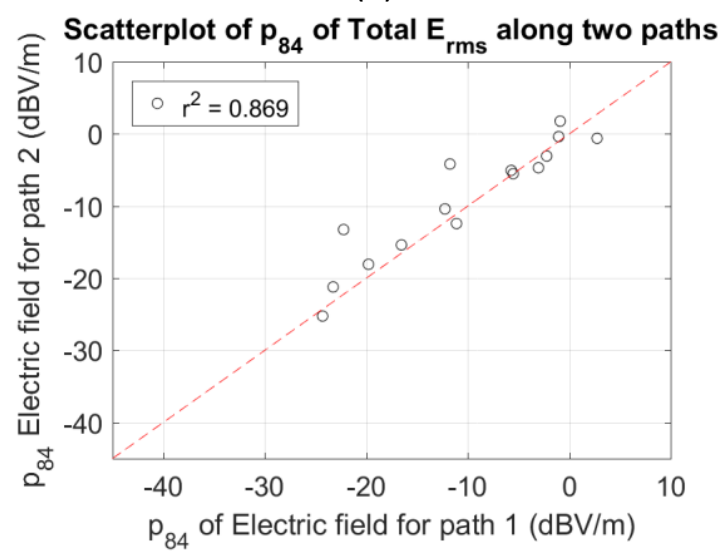

(c)

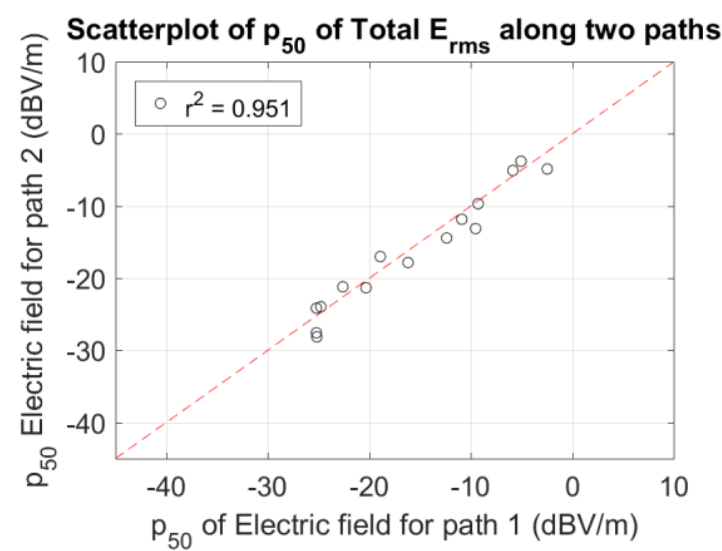

(b)

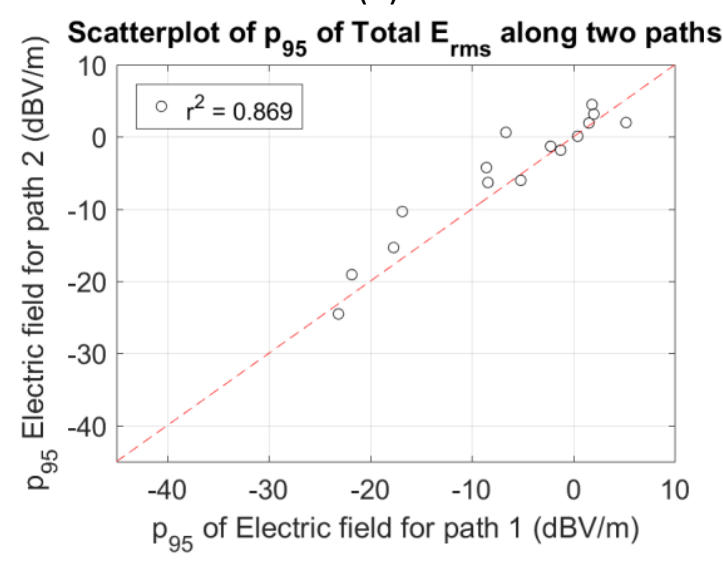

(d)

Figure 4: Scatterplots of the (a) 16\% (b) 50\% (c) 84\%, and (d) 95\% percentiles of the Total Measured $E_{r m s}$ in 15 preselected microenvironments in which two paths are defined. The vertical axis shows the statistics for the second path, whereas the horizontal axis shows the statistics for the first path. The values are obtained by pooling all measurement data (5 repetitions) for separate paths in separate microenvironments.

Table 3 shows the correlation coefficients obtained for all studied quantities and exposure metrics for simultaneously performed measurements, non-simultaneously performed measurements, and the pooled results. The highest correlations are obtained for the pooled results $\left(\mathrm{r}^{2}>0.87\right.$ for total RF-EMF exposure). The non-simultaneous measurements generally result in higher correlations between the summary statistics than the simultaneous measurements, except some percentiles in 'Broadcast' and 'Other' RF-EMF exposure. 
The same measurement samples that were used to obtain the summary statistics that are shown in Figure 4 (all measured data pooled per area), are evaluated using the WRS test. In all areas except areas 2, 6 and 9, median 'DL' exposure levels obtained along both paths were significantly different [area $2(\mathrm{p}=0.05)$, area $6(\mathrm{p}=0.13)$, and area $9(\mathrm{p}=0.17)]$. Similarly, median 'UL' exposure levels obtained along both paths were significantly different in all areas except areas 1 and 11 [area $1(\mathrm{p}=0.22)$ and area $11(\mathrm{p}=0.14)$ ]. 'Broadcast' exposure levels obtained along both paths were significantly different in all areas except areas 2 and 4 [area 1 $(\mathrm{p}=0.92)$ and area $4(\mathrm{p}=0.86)]$. Furthermore, 'Other' exposure levels obtained along both paths were significantly different in all areas except area $8(\mathrm{p}=0.85)$. Also, 'Total' exposure levels obtained along both paths were significantly different in all areas except area $9(p=0.96)$. Similar results were obtained when the data were split into simultaneous and non-simultaneous measurements.

Table 3. Evaluation of the representativeness of personal exposure measurements. Spearman correlations are shown between summary statistics obtained by measurements performed along two paths in the same microenvironment (Simultaneous: samples measured during the two simultaneous repetitions are pooled (single exposimeters on two subjects), Nonsimultaneous: samples measured during the three other repetitions are pooled (average over two ExpoMs on two subjects), Five repetitions: all measurements along the same path are pooled).

\begin{tabular}{|c|c|c|c|}
\hline Quantity & \multicolumn{3}{|c|}{ Spearman $r^{2}\left(p-\text { value }^{a}\right)^{b, c}$} \\
\hline & Simultaneous & Non-Simultaneous & Five repetitions \\
\hline \multicolumn{4}{|c|}{ (3) } \\
\hline$\mu$ & 0.85 & 0.81 & 0.87 \\
\hline$p_{16}$ & 0.84 & 0.88 & 0.89 \\
\hline$p_{50}$ & 0.91 & 0.96 & 0.97 \\
\hline$p_{84}$ & 0.80 & 0.84 & 0.84 \\
\hline$p_{95}$ & 0.71 & 0.72 & 0.85 \\
\hline \multicolumn{4}{|l|}{ UL } \\
\hline$\mu$ & 0.79 & 0.93 & 0.91 \\
\hline$p_{16}$ & 0.81 & 0.95 & 0.90 \\
\hline$p_{50}$ & 0.88 & 0.97 & 0.92 \\
\hline$p_{84}$ & 0.82 & 0.94 & 0.94 \\
\hline$p_{95}$ & 0.80 & 0.86 & 0.86 \\
\hline \multicolumn{4}{|l|}{ Broadcast } \\
\hline$\mu$ & 0.79 & 0.92 & 0.92 \\
\hline$p_{16}$ & $0.42(0.02)$ & 0.77 & 0.82 \\
\hline$p_{50}$ & 0.82 & 0.94 & 0.76 \\
\hline$p_{84}$ & 0.95 & 0.90 & 0.90 \\
\hline$p_{95}$ & 0.78 & 0.86 & 0.88 \\
\hline \multicolumn{4}{|l|}{ Other } \\
\hline$\mu$ & 0.74 & 0.63 & 0.66 \\
\hline$p_{16}$ & $0.52(0.01)$ & 0.76 & 0.70 \\
\hline$p_{50}$ & 0.86 & 0.90 & 0.82 \\
\hline$p_{84}$ & 0.73 & 0.79 & 0.82 \\
\hline$p_{95}$ & 0.64 & 0.52 & 0.60 \\
\hline \multicolumn{4}{|l|}{ Total } \\
\hline$\mu$ & 0.86 & 0.85 & 0.90 \\
\hline$p_{16}$ & 0.88 & 0.80 & 0.93 \\
\hline$p_{50}$ & 0.93 & 0.94 & 0.95 \\
\hline$p_{84}$ & 0.82 & 0.88 & 0.87 \\
\hline$p_{95}$ & 0.66 & 0.87 & 0.87 \\
\hline
\end{tabular}

${ }^{\mathrm{a}} \mathrm{p}$ value is $<0.01$ unless mentioned otherwise.

${ }^{\mathrm{b}}$ Correlations are calculated using logarithmic $(\mathrm{dB})$ values. No observations $=15$.

${ }^{c}$ The correlations are determined for the following statistics: the mean $(\mu)$ and four percentiles the 16th, 50th , 84th, and 95th percentiles, indicated by $\mathrm{p} 16, \mathrm{p} 50, \mathrm{p} 84$, and $\mathrm{p} 95$, respectively, of the $\mathrm{E}_{\mathrm{rms}}$ measured along two paths. 


\subsection{Repeatability of Microenvironmental Measurements}

All the studied paths (2) in all microenvironments (15) were repeated five times. Table 3 shows the correlation between different summary statistics obtained during two different repetitions of each path. The correlations shown in Table 4 are calculated using 30 observations (15 microenvironments $\mathrm{x} 2$ paths) where for each considered path a random repetition was drawn. This process was repeated a 100 times and led to the average correlations shown in Table 4.

Table 4. Evaluation of the repeatability of personal exposure measurements. The average of the Spearman correlations are shown between summary statistics obtained by measurements performed along the paths in the same microenvironment at a different time instance.

\begin{tabular}{|c|c|c|c|c|c|}
\hline & \multicolumn{5}{|c|}{ Average Spearman $\mathbf{r}^{2}(\mathbf{s t d})^{\mathbf{a}, \mathbf{b}}$} \\
\hline & DL & UL & Broadcast & Other & Total \\
\hline$\mu$ & $0.91(0.04)$ & $0.94(0.02)$ & $0.74(0.06)$ & $0.80(0.05)$ & $0.91(0.04)$ \\
\hline$p_{16}$ & $0.94(0.01)$ & $0.93(0.02)$ & $0.39(0.11)$ & $0.39(0.09)$ & $0.84(0.05)$ \\
\hline$p_{50}$ & $0.95(0.02)$ & $0.93(0.02)$ & $0.64(0.08)$ & $0.75(0.08)$ & $0.93(0.04)$ \\
\hline$p_{84}$ & $0.91(0.03)$ & $0.95(0.02)$ & $0.77(0.06)$ & $0.83(0.04)$ & $0.91(0.03)$ \\
\hline$p_{95}$ & $0.84(0.06)$ & $0.92(0.03)$ & $0.86(0.04)$ & $0.75(0.06)$ & $0.87(0.05)$ \\
\hline b The & are calculate & bed using th & $\begin{array}{l}(\mathrm{dB}) \text { values. } \\
\text { petitions. } \\
\text { ollowing statis } \\
\text { les the } 16 \text { th }, 5\end{array}$ & observations & $\begin{array}{l}\text { 30. Average is } \\
\text { the standard } \\
\text { th percentiles, }\end{array}$ \\
\hline
\end{tabular}

The average and median exposure were highly reproducible for all studied quantities $\left(\mathrm{r}^{2}>0.64\right)$. All summary statistics were highly reproducible for DL $\left(\mathrm{r}^{2}>0.84\right)$, UL $\left(\mathrm{r}^{2}>0.92\right)$, and Total Exposure $\left(r^{2}>0.84\right)$. The $\mathrm{p}_{16}$ values were less reproducible for Broadcast $\left(\mathrm{r}^{2}=0.39\right)$ and Other RF-EMF exposure $\left(\mathrm{r}^{2}=0.39\right)$, while the other percentiles and the arithmetic average were highly reproducible as well $\left(\mathrm{r}^{2}>0.64\right)$. All $\mathrm{p}$ values of the individual correlations were lower than or equal to 0.02 .

\subsection{Comparison of two simultaneously used ExpoM-RF devices}

Table 5 shows the correlations between summary statistics obtained from simultaneous measurements using two ExpoM-RF devices. Summary statistics were obtained from pooled measurements of three repetitions of two paths in 13 microenvironments, and five repetitions of two paths in two microenvironments (the industrial area and suburban area 6).

Table 5. Correlation between summary statistics of personal exposure measurements executed using two ExpoM-RF devices that are worn simultaneously on the body. Spearman correlations are shown between summary statistics obtained from simultaneous measurements performed using two different ExpoM-RF devices. The summary statistics were obtained for all paths and repetitions in the same microenvironment where two ExpoMs were worn simultaneously by the same researcher.

\begin{tabular}{c|ccccc}
\hline & \multicolumn{5}{|c|}{ Average Spearman $\mathbf{r}^{\mathbf{2} \mathbf{a}, \mathbf{b}, \mathbf{c}}$} \\
\hline & DL & UL & Broadcast & Other & Total \\
\hline $\boldsymbol{\mu}$ & 0.96 & 0.95 & 0.92 & 0.94 & 0.94 \\
$\boldsymbol{p}_{\mathbf{1 6}}$ & 0.92 & 0.94 & 0.69 & 0.86 & 0.95
\end{tabular}




\begin{tabular}{|c|c|c|c|c|c|}
\hline$p_{50}$ & 0.97 & 0.96 & 0.84 & 0.91 & 0.96 \\
\hline$p_{84}$ & 0.94 & 0.96 & 0.84 & 0.97 & 0.93 \\
\hline$p_{95}$ & 0.97 & 0.93 & 0.94 & 0.95 & 0.96 \\
\hline \multicolumn{6}{|c|}{$\begin{array}{l}\text { a all } p \text { value are }<0.01 \text {. } \\
{ }^{b} \text { Correlations are calculated using logarithmic }(\mathrm{dB}) \text { values. No observations }=15 \text {. } \\
{ }^{\mathrm{c}} \text { The correlations are determined for the following statistics: the mean }(\mu) \text {, and four percentiles } \\
\text { the } 16 \text { th }, 50 \text { th }, 84 \text { th, and } 95 \text { th percentiles, indicated by } \mathrm{p}_{16}, \mathrm{p}_{50}, \mathrm{p}_{84} \text {, and } \mathrm{p}_{95} \text {, respectively, of } \\
\text { the } \mathrm{E}_{\mathrm{rms}} \text { measured using two devices. }\end{array}$} \\
\hline
\end{tabular}

All studied percentiles and the mean showed very high correlations $\left(\mathrm{r}^{2}>0.69\right)$ for all studied exposure quantities.

\subsection{Comparison of the PDE-Helmet and the ExpoM-RFs measurements}

Twenty eight simultaneous measurements using both the PDE-Helmet and either one or two ExpoMs-RF were conducted. Summary statistics were determined for the 28 measurements and correlated. These are shown in Figure 5.

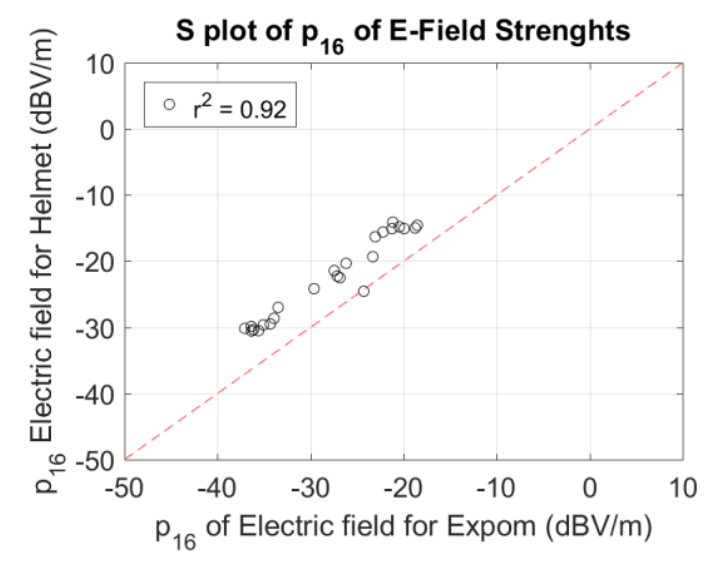

(a)

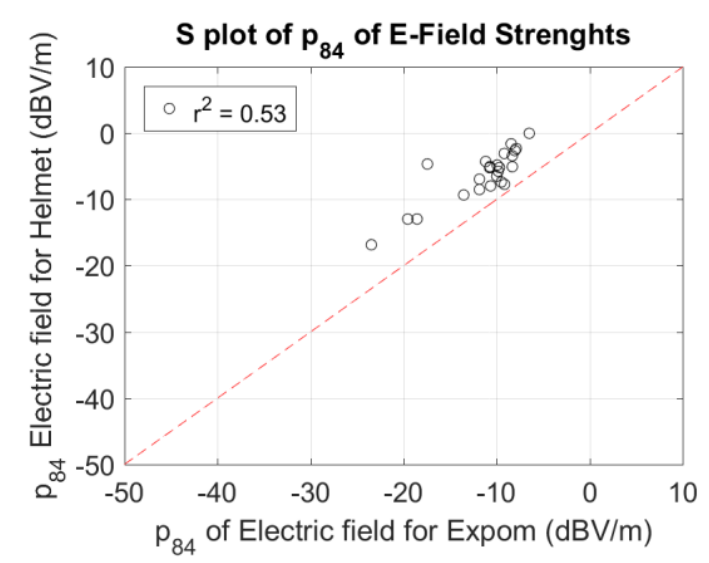

(c)

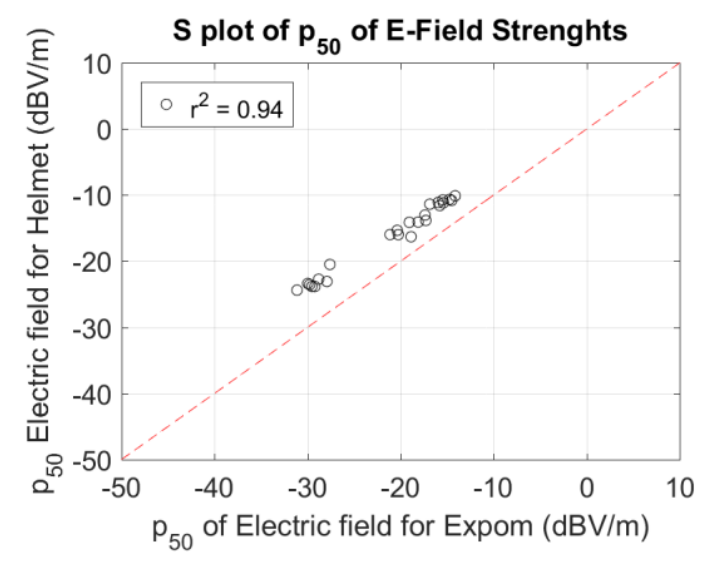

(b)

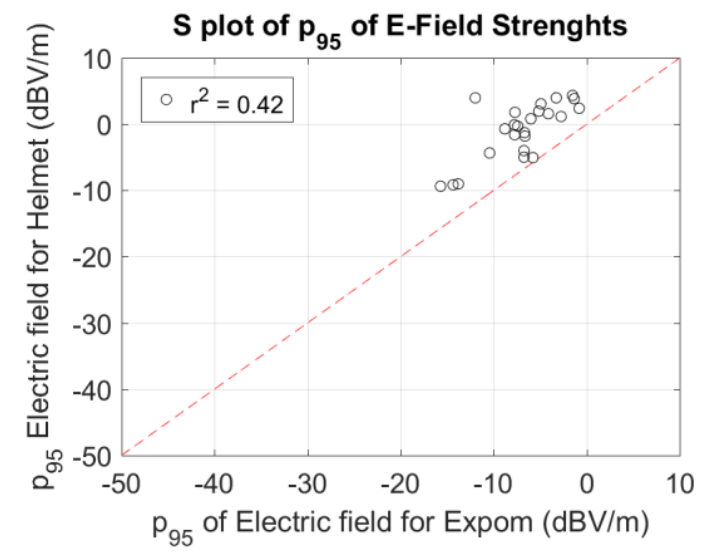

(d)

Figure 5: Scatterplots of the (a) $16 \%$ (b) $50 \%$ (c) $84 \%$, and (d) $95 \%$ percentiles of the Electric Field Strength in the GSM 900 DL band. Measured using body-worn ExpoM-RFs (horizontal axis) and the PDE-Helmet (vertical axis) in 3 preselected microenvironments in which 2 paths are repeated 4 times. In this case all the presented results were obtained simultaneously and by the same researcher. 
The median values measured using the PDE-Helmet were in between $0.06 \mathrm{~V} / \mathrm{m}$ and $0.31 \mathrm{~V} / \mathrm{m}$. We obtained very high correlations between both measurement devices, up to $\mathrm{r}^{2}=0.94$ for the median values. The measurements using the PDE-Helmet were approximately $5 \mathrm{~dB}$ higher than those obtained using the ExpoM-RF(s).

\section{Discussion}

We have conducted personal RF-EMF measurements using two different types of measurement devices in fifteen microenvironments in Melbourne, Australia. These are some of the first findings that demonstrate representativeness and repeatability of microenvironmental RF-EMF measurements over time. Moreover, our measurement results are the first to present a validation of the commonly used measurement devices in the field.

\subsection{Personal RF Exposure in Melbourne, Australia}

We reported RF-EMF exposure levels in terms of Electric Field Strength $(\mathrm{V} / \mathrm{m})$ in fifteen microenvironments, six modes of transportation between the measurement sites, and six other points of interest in Melbourne, Australia. We observed variations according to the RF-EMF considered (DL, UL, Broadcast, Other, and Total RF-EMF exposure), the type and location of the microenvironment that was considered, the type of transport that was used, and the measurement time of day.

Different proportions of non-detects were observed in different frequency bands (see Table 1 and Table C. 1 in Appendix C). The lowest percentages (0.2\% - 42\%) of measurements falling underneath the LOS were found for the DL bands and TV. This was to be expected as these are broadcast signals, which are present in any environment in which RF-EMF telecommunication could be used. The $900 \mathrm{DL}, 1800 \mathrm{DL}, 2100 \mathrm{DL}$, and (to a lesser extent) the DVB-T band showed very low percentages of non-detects across all studied microenvironments, modes of transport, and places of interest. The $800 \mathrm{DL}$ and $2600 \mathrm{DL}$ bands showed very low percentages of non-detects in the areas 1- 6 close to the CBD, whereas their percentages of non-detects seem to increase in other areas. We hypothesize that these bands, which have been allocated for telecommunication more recently than the other frequency bands, are currently being used only in more dense areas where additional capacity had to be installed by the telecom network providers. The highest percentages of non-detects were found for the uplink bands 1800 UL, 2100 UL, 2600 UL, FM, and WiMax (74\% - 94\%). The WiMax band is an infrequently used band (Bhatt et al., 2016b). Table C.1 demonstrates that we observed very high percentages of non-detects in this band in almost all areas. UL seems to be used more often at lower frequencies $800 \mathrm{UL}$ (37\% non-detects) and $900 \mathrm{UL}$ (7\% non-detects) in the microenvironments we studied. As these bands showed a lower path-loss, a logical choice for a mobile telecommunications operator is to perform UL at lower frequencies. One should also note that the persons who carried out the measurements were not allowed to use personal RF devices, which automatically increased the percentage of non-detects in the UL bands. Bhatt et al. (2016b) also found very low proportions of non-detects in the TV and DL bands and, in line with our findings, found the highest proportions of non-detects in the WiMax and UL bands.

We observed variations according to type and location of microenvironment. The areas (1-6) in the central business district of Melbourne were those with the highest total RF-EMF 
exposure (means between 0.39 and $0.89 \mathrm{~V} / \mathrm{m}$ ). These are areas with high population densities (during the time of measurements) and consequently users of RF-EMF sources. A lower total RF-EMF exposure was observed in the (sub-) urban areas (8-12) close to the CBD (South Melbourne, Hawthorne, Windsor and Prahran). These are areas with less population density than those areas in the CBD (ABS, 2016), but with moderate activity during the time of measurements. There are a number of base station antennas in these areas and there were many permanent users of RF-EMF technologies in the vicinity of the researchers. In contrast, there were almost no other users present along the measurement paths in the outer suburban areas in Werribee (13 and 14). Consequently, most of the RF-EMF exposure is generated by providers of telecommunication services. This resulted in the lowest RF-EMF exposure values. The two areas which were measured by car also resulted in relatively low exposure values. As we point out in the next paragraphs, we attribute this mainly to the type of transportation.

Similar variations between microenvironments were observed in earlier studies. Bhatt et al. (2016b) performed measurements in Melbourne and also observed the highest total RF-EMF exposure values in the CBD, while RF-EMF exposure was lower in the urban/suburban areas surrounding the CBD, and the lowest exposure was measured in rural areas near the city. Sagar et al. (2016) found the highest total RF-EMF exposure in city centers in Switzerland in comparison to central residential areas and rural areas (lowest exposure). Urbinello et al. (2014) also found that total RF-EMF exposure was higher in central areas in comparison to residential areas in four out of five European cities that were considered in their study.

We observed large variations in RF-EMF exposure depending on the type of transportation that is used. This occurred for the microenvironments 1 to 15 and during transportation between those microenvironments. Driving a car generally causes the lowest total RF-EMF exposure. However, we should note that in our case the researcher was not using any RF-EMF emitting devices in the car, whereas this seems unlikely for real users. Surprisingly, the measurements obtained in public transports such as train, tram, and bus, resulted in lower exposures than those obtained using bike or walking between microenvironments. We attribute this to the fact that we mainly used buses and trains to get to and from rural and suburban areas outside of the CBD, where RF-EMF exposure was found to be highest, while walking and biking occurred mainly in or near the CBD (shorter distances travelled). The fact that we observed higher total exposure in the tram, which runs mainly in or close to the CBD, than in the train, seems to confirm this. We also observed higher relative contributions of UL and Other types of exposure during the car and public transport measurements, in comparison to those obtained using walking and biking. This can be explained by the shielding from the outer layers of the vehicles, which blocks part of the DL signals and thus lowers their relative contributions (Aerts et al. 2013).

Bhatt et al. (2016b) studied the same modes of transportation in the city of Melbourne and observed similar findings: walking or riding a bike in Melbourne resulted in higher RF-EMF exposure than taking the tram, bus or train in the same city. Sagar et al. (2016) found the highest levels of RF-EMF exposure during tram rides, followed by train and bus, but they did observe much higher relative contributions of UL to the total exposure during public transport in Switzerland, than what we observed in Australia. Bolte and Eikelboom (2012) observed higher total levels of RF-EMF exposure during train, tram, car, and metro rides in the Netherlands in comparison to biking or walking outdoor. This was mainly caused by higher UL levels (their subjects were allowed to use a mobile phone). 
We observed small but significant differences between measurements at different times of day. Exposure was generally found to be higher around midday and in the afternoon, in comparison to measurements in the morning. Broadcast exposure was the only component that remains constant throughout all time intervals. Bolte and Eikelboom (2012) found higher RF-EMF exposure values in the evening (18h-23h) than during daytime (07h-18h), but did not distinguish between different times within the day. Urbinello et al. (2014) found that the time of day could only explain a very small fraction $(0.2 \%)$ of the variation in total RF-EMF exposure in comparison to city (50\%) and areas within the city $(30 \%)$ which explained much larger proportions of the variation. We observed a similar effect where the variation between our different microenvironments (see Fig. 2) was larger than the variation between times of day (see Fig. 3).

All measured RF-EMF exposure levels were below the reference levels for the general public as defined in the guidelines of the International Commission on Non-Ionizing Radiation Protection (ICNIRP, 1998). The lowest reference level in the frequency band considered in this study was $28 \mathrm{~V} / \mathrm{m}$, while the maximally measured $\mathrm{p}_{95}$ found in all of our considered microenvironments was $1.5 \mathrm{~V} / \mathrm{m}$. Furthermore, our measured RF-EMF electric field strength values are comparable to those obtained by Bhatt et al. (2016b). A similar study design in Melbourne (Bhatt et al., 2016b) resulted in mean total exposures in outdoor environments between $0.02 \mathrm{~V} / \mathrm{m}$ and $4.5 \mathrm{~V} / \mathrm{m}$, measured with a pair of on-body calibrated ExpoM-RF on the

hips of a researcher. Our outdoor measurements resulted in total mean RF-EMF exposure values between $0.05-0.89 \mathrm{~V} / \mathrm{m}$, which were measured with an ExpoM-RF which was not calibrated on the body and therefore prone to measure lower values due to body shielding (Thielens et al., 2013).

\subsection{Representativeness}

We studied representativeness of our measurement protocol by comparing summary statistics obtained along different paths in the same microenvironments. We obtained high correlations for five repetitions of the path on five different times of day (all $\left.\mathrm{r}^{2}>0.60\right)$. This indicated that a single path would suffice to provide representative summary statistics for the studied microenvironments. These results are in line with those published elsewhere (Sagar et al., 2016), where correlations between $r=0.55$ for UL up to $r=0.85$ were found in different cities in Switzerland.

The WRS test showed significant differences between measurements obtained along two paths in the same microenvironment in most studied areas. The high correlation between the summary statistics obtained in 15 microenvironments suggest that, although significant differences might be found in single areas, the set of summary statistics obtained over all studied microenvironments does not depend on the chosen path.

Surprisingly, we found that non-simultaneous repetitions (3 repetitions) resulted in higher correlations than simultaneously ( 2 repetitions) performed measurements along two paths. Our analysis showed that this is mainly due to lower correlations in UL exposure. A similar lower correlation was also found for two repetitions by Sagar et al. (2016). This might indicate that stable summary statistics for UL exposure need more repetitions spread over different times of 
day and different days of the week. Our time-of-day analysis (Fig. 3) confirms that UL exposure is relatively more varying with time of day than the other types of studied exposure.

\subsection{Repeatability}

We observed a very high repeatability of our microenvironmental measurements. The summary statistics were found to correlate highly when comparing them along two different executions of the same set of 30 paths especially for DL $\left(\mathrm{r}^{2}>0.84\right)$, UL $\left(\mathrm{r}^{2}>0.92\right)$, and Total Exposure $\left(r^{2}>0.84\right)$. The $p_{16}$ values yield lower correlations for Broadcast $\left(r^{2}=0.39\right)$ and Other types of RF-EMF exposure $\left(\mathrm{r}^{2}=0.39\right)$. A priori, we expected Broadcast to be most reproducible since the emitted fields do not depend on network traffic, so these results are counter-intuitive.

These findings are very much in line with those published by Sagar et al. (2016), where high correlations ( $r=0.9$ for DL and Total exposure) were found for two repetitions of the same path. Bhatt et al. (2016b) observed high correlations ( 0.73 for DL and 0.74 for total exposure) for median exposure obtained along two repetitions of the same path in different microenvironements. Urbinello et al. (2014) also observed a very high repeatability of total DL signals along the same path in different European cities.

\subsection{Comparison of two simultaneously used ExpoM-RF devices}

We found very high positive correlations between summary statistics obtained from simultaneous measurements using two ExpoM-RF devices (Table 5). This was expected as both ExpoM-RF devices were placed on the same positions on the body and had the same hardware and calibration. These high correlations serve as an additional validation of the dosimetric measurements.

\subsection{Comparison of the PDE-Helmet and the ExpoM-RFs measurements}

We found high correlations between PDE-Helmet and ExpoM-RFs (Figure 5). This indicates that for this study design, both devices would provide similar summary statistics. We interpret this as a very strong internal validation of our measurement devices, which were calibrated and designed by independent manufacturers. It should be noted that these values contain some intrinsic correlation because they come from repeated measurements of six paths.

The measurements using the PDE-Helmet are approximately $5 \mathrm{~dB}$ higher than those obtained using the Expom-RF(s). Bhatt et al. (2016b) found an underestimation of 6-7 dB for the ExpoM-RFs. Aminzadeh et al. (2017) and Thielens et al. (2015) found $5 \mathrm{~dB}$ underestimation in the 900 DL band for commercial PEMs: the ExpoM-RF and the EME SPY, respectively, very much in line with our results.

The measurement uncertainty of the ExpoM-RF caused by the presence of the human body was not measured in this particular study. Previous studies list $68 \%$ confidence intervals of 9.7 $\mathrm{dB}$ (Bhatt et al., 2016b) and $9.3 \mathrm{~dB}$ (Aminzadeh et al., 2017) for the estimated power densities using a single ExpoM-RF in the 900 DL band. It is expected that this would be decreased by at least $3 \mathrm{~dB}$ when averaging over two devices (Thielens et al., 2016; Bhatt et al., 2016b). Our 
calibration (appendix B) shows a $68 \%$ confidence interval of $4.9 \mathrm{~dB}$ on the values measured using the PDE-Helmet.

\subsection{Strengths, limitations, and implications}

This study provides very important results for the interpretation and design of microenvironmental exposure study of RF-EMF exposures. The main strengths of this study are: First, we demonstrated a high representativeness of the study approach, which for the first time was investigated using actual simultaneous measurements; Second, we showed that the measurements were repeatable over time. These two findings could be used to design future exposure assessment studies more efficiently; Third, we found very high correlations between measurements in the 900 DL band, obtained by using two independent measurement devices simultaneously. We saw this as a strong validation of our measurements; Fourth, we demonstrated in real environments that there was an offset caused by body shielding between a PEM calibrated on the body/head (PDE-Helmet) and another PEM (ExpoM-RF), which was calibrated in free space. These results have previously been demonstrated in a controlled measurement environment (such as a test or calibration setup), but were clearly demonstrated here during real microenvironmental measurements. Bhatt et al. (2016b) found similar percentages in most bands, except for the $800 \mathrm{UL}$ and DL bands, which seem to show lower percentages of non-detects in our current study. This could indicate that the $800 \mathrm{UL}$ band, which was originally intended for $4^{\text {th }}$ generation telecommunication is used more intensively in this later study.

An additional strength of our study was that the PDE-Helmet measured E-fields that were incident on the head of a subject and could be used more directly to relate to cognitive effects that could be related to exposure of the human head (Roser et al., 2016). Moreover, the PDEHelmet uses four antennas distributed over the head, which reduces the measurement uncertainty in the GSM 900 DL band, see appendix B (Fig. B.1), and decreases the chance of non-detects. During our measurements, we observed no non-detects by the PDE-Helmet in the 900 DL band, which is an advantage since non-detects have been reported to be a problem in other RF-EMF exposure studies (Röösli et al., 2010; Bolte et al., 2016).

The selection of microenvironments was done in order to generate a representative set for RFEMF exposure in Melbourne. Other microenvironmental studies consider similar numbers of microenvironments within a city (Sagar et al., 2016; Urbinello et al. 2014; Bhatt et al., 2016). However, we have not been able to demonstrate representativeness for all microenvironments that could be found in the greater Melbourne area. In a future evaluation, we would like to follow a more systematic approach in which inter class (for example: CBD, suburban, etc.) validity is investigated by adding new microenvironments within a certain class and see whether the obtained statistics are representative for exposure in that new microenvironment.

The main limitations of this study were: First, the ExpoM-RF devices were not calibrated on the body, which is associated with an underestimation of exposure and a larger measurement 
uncertainty; Second, the presence of non-detects could not be avoided in the measurements; and iii) the PDE-Helmet only measured in the 900 DL frequency band.

The ExpoM-RFs were not calibrated on the bodies of the researchers performing the measurements. It has been demonstrated (Bolte et al., 2016; Gajšek et al., 2015; Iskra et al., 2011; Neubauer et al., 2010; Thielens et al., 2015) that this leads to an underestimation of exposure and a higher relative measurement uncertainty. We have chosen to work with ExpoMRF exposimeters (calibrated in free space and not on the body) for the following reasons: firstly, we have already calibrated the same devices on the body (Bhatt et al., 2016) and could use these calibration results in the interpretation of our measurements. Secondly, we have undertaken measurements using two ExpoM-RF devices simultaneously in a majority of our measurements. We have previously demonstrated that this configuration reduces the measurement uncertainty (Bhatt et al., 2016). Thirdly, our main goals - determining representativeness and repeatability - were independent of using an on-body calibration. However, as our comparison with the PDE-Helmet showed, there was an underestimation associated with this approach.

We chose to work with substitution of non-detects below the LOD by LOD $/ \sqrt{2}$ (Ganser and Hewett, 2010). Different substitution methods are discussed and compared elsewhere (Hewett and Ganser, 2007). Substitution by LOD $/ \sqrt{2}$ could lead to some bias in summary statistics for some distributions. However, the relatively simple method does not lead to much loss in accuracy in comparison to higher order substitution methods (Hewett and Ganser, 2007).

Substitution by LOD/ $\sqrt{2}$ has been used in other microenvironmental personal RF-EMF exposure studies (Bhatt et al., 2016b; Sagar et al., 2016). The highest effect of this substitution would be expected in the frequency bands where most censoring occurs, see Table 1. These frequency bands have relatively small contributions to the total exposure (see Table 2), so we expect a very small effect from the substitution method on the total exposure.

The PDE-Helmet used for the first time in this study has shown some considerable advantages over the previous prototypes of the same measurements devices. The device is much smaller and more wearable than the one used in Bhatt et al. (2016b). A disadvantage of the PDE-Helmet is that is difficult to use when one is not riding a bicycle. It is our future goal to integrate the same number of frequency bands as measured by the ExpoM-RF in the same small form-factor, which should enable a researcher to do measurements in all RF-EMF frequency bands with smaller measurement uncertainties and with no body shielding effect.

\section{Conclusions}

This study revealed variations of personal RF-EMF exposure depending on the considered microenvironment within Melbourne and the time of day, in which the morning resulted in lower exposure values in all studied exposure groups, except Broadcast RF-EMF exposure. The summary statistics obtained from measurements along a path in 15 microenvironments showed high correlations with those obtained from measurements along another path in the same environments. This indicates that the proposed measurement procedure is representative 
for the selection of microenvironments used to characterize Melbourne in this study. The summary statistics also show high correlations with those obtained during repeated measurements of the same paths, which indicated repeatability of our methodology over time. The results obtained during simultaneous measurement using the PDE-Helmet and the ExpoM$\mathrm{RF}$ show high correlations, which serve as a validation of the measurement devices. We observed an underestimation of RF-EMF exposure measured by the ExpoM-RF in the $900 \mathrm{DL}$ band, in line with previous studies. Overall, the measured RF-EMF exposure in Melbourne was low in comparison to the general public reference levels and tends to be higher in crowded areas such as the central business district than less crowed areas.

\section{Acknowledgements}

This research has received funding from the research Foundation Flanders (FWO) under grant agreement K228216N.

This project has received funding from the European Union's Horizon 2020 research and innovation programme under the Marie Skłodowska-Curie grant agreement No 665501 with the research Foundation Flanders (FWO). AT is an FWO [PEGASUS $]^{2}$ Marie Skłodowska-Curie Fellow.

This research was supported by the Centre for Population Health Research on Electromagnetic Energy (PRESEE), Department of Epidemiology and Preventive Medicine, School of Public Health and Preventive Medicine, Monash University. The centre is funded by a Centre of Research Excellence grant from the National Health and Medical Research Council, Australia(APP1060205). 


\section{REFERENCES}

Aminzadeh, R. Thielens, A., Bamba, A., Kone, L., Gaillot, D.P., Lienard, M., Martens, L, Joseph, W. 2016. On-body calibration and measurements using personal radiofrequency exposimeters in indoor diffuse and specular environments. Bioelectromagnetics 37 (5): 298-309.

Aminzadeh, R., Thielens, A., Agneessens, A., Van Torre, P., Van den Bossche, M., Dongus,S., Eeftens, M., Huss, A., Vermeulen, R., de Seze, R., Mazet, P., Cardis, E., Rogies, H., Röösli, M., Martens, L., Joseph., W. 2017. Radio-Frequency Exposure meter: Design, On-body Calibration and Study of Body Morphology. Submitted to Sensors.

Abramson MJ, Benke GP, Dimitriadis C, Inyang IO, Sim MR, Wolfe RS, et al. 2009.Mobile telephone use is associated with changes in cognitive function in young adolescents. Bioelectromagnetics 30(8):678-86.

Australian Bureau of Statistics. 2016. 3218.0 Regional Population Growth, Australia: Table 2. Estimated Resident Population, Statistical Areas Level 2, Victoria. Accessed on: www.abs.gov.au on September $20^{\text {th }} 2017$.

Beekhuizen, J., Vermeulen, R., Kromhout, H., Bürgi, A., Huss, A. 2013. Geospatial modelling of electromagnetic fields from mobile phone base stations. Science of the Total Environment 445-446: 202-209.

Bhatt, C.R., Thielens, A., Redmayne, M., Abramson, Billah, B., M.J., Sim, M.R., Vermeulen, R., Martens, L., Joseph, W., Benke, G., 2016a. Measuring personal exposure from $900 \mathrm{MHz}$ mobile phone base stations in Australia and Belgium using a novel personal distributed exposimeter. Environment International 92-93 : 388-397

Bhatt, C.R., Thielens, A., Billah, B., Redmayne, M., Abramson, M.J., Sim, M.R., Vermeulen, R., Martens, L., Joseph, W., Benke, G., 2016b. Assessment of personal exposure from radio frequency- electromagnetic fields in Australia and Belgium using on-body Calibrated exposimeters. Environmental Research 151: 547-563

Bhatt, C.R., Benke, G., Smith, C.L., Redmayne, M., Dimitriadis, C., Dalecki, A., Macleado, S., Sim, M.R., Croft, R.J., Wolfe, R., Kaufman, J., Abrahamson, M. J. 2017. Use of mobile and cordless phones and change in cognitive function: a prospective cohort analysis of Australian primary school children. Environmental Health 16 (1), 62.

Bolte, J.F.B., Eikelboom, T., 2012. Personal radiofrequency electromagnetic field measurements in the Netherlands: Exposure level and variability for everyday activities, times of day and types of area. Environ Int. 48,133-142.

Bolte, J.F.B. 2016. Lessons learnt on biases and uncertainties in personal exposure measurement surveys of radiofrequency electromagnetic fields with exposimeters. Environment International 94: 724-735.

Fields at Work. 2017. ExpoM - RF Radio Frequency Exposure Meter. url = http://www.fieldsatwork.ch/uploads/Downloads/Expom-RF_Fact_Sheet_2017.pdf (consulted on 09/12/2017).

Gajšek, P., Ravazzani, P., Wiart, J., Grellier, J., Samaras, T., Thuróczy, G., 2015. Electromagnetic field exposure assessment in Europe radiofrequency fields $(10 \mathrm{MHz}-$ $6 \mathrm{GHz}$ ). J Expo Sci Environ Epidemiol. 25, 37-44.

Ganser, G.H.,Hewett, P., 2010.An accurate substitution method for analyzing censored data. J.Occup.Environ.Hyg.7,233-244.

Hewett,P., Ganser, G.H. 2007. A comparison of several methods for analyzing censored data. Ann.Occup.Hyg.51,611-632. 
ICNIRP, 1998. The International Commission on Non-ionizing Radiation Protection. Guidelines for limiting exposure to time-varying electric, magnetic, and electromagnetic fields ( up to $300 \mathrm{GHz}$ ). Health Phys. 74 (4), 494-522.

Iskra, S., McKenzie, R.J., Cosic, I., 2011. Monte Carlo simulations of the electric field close to the body in realistic environments for application in personal radiofrequency dosimetry. Radiat Prot Dosimetry. 147, 517-527.

Joseph, W., Frei, P., Roösli, M., Thuróczy, G., Gajsek, P., Trcek, T., Bolte, J., Vermeeren, G., Mohler, E., Juhász, P., Finta, V., Martens, L., 2010. Comparison of personal radio frequency electromagnetic field exposure in different urban areas across Europe. Environ Res. 110, 658-663.

Kheifets, L., Repacholi, M., Saunders, R., van Deventer, E. 2005. The Sensitivity of Children to Electromagnetic Fields. Pediatrics 116.

Neubauer, G., Cecil, S., Giczi, W., Petric, B., Preiner, P., Fröhlich, J.,Röösli, M., 2010. The association between exposure determined by radiofrequency personal exposimeters and human exposure: a simulation study. Bioelectromagnetics 31, 535-545.

Röösli, M., Frei, P., Mohler, E., Braun-Fährländer C., Bürgi, A., Fröhlich, J., Neubauer, G., Theis, G., Egger, M. 2008. Statistical analysis of personal radiofrequency electromagnetic field measurements with nondetects. Bioelectromagnetics 29(6): 471478.

Röösli, M., Frei, P., Bolte, J., Neubauer, G., Cardis, E., Feychting, M., Gajsek, P., Heinrich, S., Joseph, W., Mann, S., Martens, L., Mohler, E., Parslow, R.C., Poulsen, A.H., Radon, K., Schuz, J., Thuroczy, G., Viel, J.F.,Vrijheid, M., 2010. Conduct of a personal radiofrequency electromagnetic field measurement study: proposed study protocol. Environ Health. 9, 23, 1-14.

Roser K, Schoeni A, Foerster M, Röösli M. 2016. Problematic mobile phone use of Swiss adolescents: is it linked with mental health or behaviour? International journal of public health, 2016:1-9

Rowley, J.T., Joyner, K.H., 2012. Comparative international analysis of radiofrequency exposure surveys of mobile communication radio base stations. J Expo Sci Environ Epidemiol. 22, 304-315.

Sagar, S., Struchen, B., Finta,V., Eeftens, M., Röösli, M. 2016.Use of portable exposimeters to monitor radiofrequency electromagnetic field exposure in the everyday environment. Environ. Res 150,289-298.

Thielens, A., De Clercq, H., Agneessens, S., Lecoutere, J., Verloock, L., Declercq, F., Vermeeren, G., Tanghe, E., Rogier, H.,Puers, R., 2013. Personal distributed exposimeter for radio frequency exposure assessment in real environments. Bioelectromagnetics 34, 563-567.

Thielens, A., Agneessens, S., Verloock, L., Tanghe, E., Rogier, H., Martens, L., Joseph,W. 2015. On-body Calibration and Processing for a Combination of Two Radio Frequency Personal Exposimeters. Radiation Protection Dosimetry, 163, 58-69.

Thielens, A., Vanveerdeghem, P., Van Torre, P., Gängler, S., Röösli, M., Rogier, H., Martens, L., Joseph, W., 2016. A Personal, Distributed Exposimeter: Procedure for Design, Calibration, Validation, and Application. Sensors 16, 180.

Urbinello, D., Joseph, W., Verloock, L., Martens, L., Röösli, M., 2014a. Temporal trends of radio-frequency electromagnetic field (RF-EMF) exposure in everyday environments across European cities. Environ Res. 134, 134-142.

Urbinello, D., Joseph, W., Huss, A., Verloock, L., Beekhuizen, J., Vermeulen, R., Martens, L.,Roosli, M., 2014b. Radio-frequency electromagnetic field (RF-EMF) exposure levels in different European outdoor urban environments in comparison with regulatory limits. Environ Int. 68, 49-54. 
Urbinello, D., Huss, A., Beekhuizen, J., Vermeulen, R., Röösli, M., 2014c. Use of portable exposure meters for comparing mobile phone base station radiation in different types of areas in the cities of Basel and Amsterdam. Sci Total Environ. 468-469:10281033.

van Deventer, E., van Rongen, E.,Saunders, R., 2011. WHO research agenda for radiofrequency fields. Bioelectromagnetics 32, 417-421.

Vanveerdeghem, P., Vantorre, P., Thielens, A., Knockaert, J., Joseph, W., Rogier, H. 2015. Compact Personal Distributed Wearable Exposimeter. IEEE Sensors Journal 15(8), 4393-4401.

\section{Appendix A}

Table 1: Location sites of the studied microenvironments and places of interest, site characteristics, the estimated resident population density (ABS, 2016), and activities or modes of transportation.

\begin{tabular}{|c|c|c|c|c|c|}
\hline Microenvironments & Alias & County & $\begin{array}{l}\text { Study sites and } \\
\text { characteristics }\end{array}$ & $\begin{array}{l}\text { Estimated } \\
\text { Resident } \\
\text { Population } \\
\text { Density } \\
\text { (persons / } \\
\text { km²) }^{2} \\
\end{array}$ & Activities \\
\hline 1 & $\begin{array}{l}\text { Park close } \\
\text { to CBD } 1\end{array}$ & South Yarra & $\begin{array}{l}\text { Fawkner Park \& } \\
\text { King's Domain; } \\
\text { Public parks and } \\
\text { green areas; Low } \\
\text { concentration of } \\
\text { buildings. }\end{array}$ & 4741 & $\begin{array}{l}\text { Riding a } \\
\text { bicycle }\end{array}$ \\
\hline 2 & $\begin{array}{l}\text { Park close } \\
\text { to CBD } 2\end{array}$ & $\begin{array}{l}\text { South } \\
\text { Melbourne }\end{array}$ & $\begin{array}{l}\text { Albert Park; Public } \\
\text { Park mainly used } \\
\text { for sports and } \\
\text { recreation; Low } \\
\text { concentration of } \\
\text { buildings. }\end{array}$ & 3550 & $\begin{array}{l}\text { Riding a } \\
\text { bicycle }\end{array}$ \\
\hline 3 & CBD 1 & $\begin{array}{l}\text { South and } \\
\text { North } \\
\text { riverbank of } \\
\text { the Yarra } \\
\text { River, } \\
\text { Melbourne }\end{array}$ & $\begin{array}{l}\text { Melbourne Central } \\
\text { Business District } \\
\text { riverside area; } \\
\text { Commercial area } \\
\text { with mainly } \\
\text { restaurants and } \\
\text { bars; Highly dense } \\
\text { urban environment. }\end{array}$ & 14965 & Walking \\
\hline 4 & $\begin{array}{l}\text { University } \\
\text { Campus } 1\end{array}$ & Parkville & $\begin{array}{l}\text { Campus of the } \\
\text { University of } \\
\text { Melbourne, north } \\
\text { of Melbourne's } \\
\text { CBD. 2-3 storey } \\
\text { buildings mainly } \\
\text { used for academic } \\
\text { purposes (teaching } \\
\text { and research). }\end{array}$ & 1854 & Walking \\
\hline 5 & CBD 2 & $\begin{array}{l}\text { Melbourne } \\
\text { CBD }\end{array}$ & $\begin{array}{l}\text { First area in the } \\
\text { Central Business } \\
\text { District (CBD) of }\end{array}$ & 14965 & Walking \\
\hline
\end{tabular}




\begin{tabular}{|c|c|c|c|c|c|}
\hline & & & $\begin{array}{l}\text { Melbourne. } \\
\text { Characterized by } \\
\text { very dense, high } \\
\text { buildings and a } \\
\text { relatively large } \\
\text { number of people } \\
\text { on the street. }\end{array}$ & & \\
\hline 6 & CBD 3 & $\begin{array}{l}\text { Melbourne } \\
\text { CBD }\end{array}$ & $\begin{array}{l}\text { Second area in the } \\
\text { Central Business } \\
\text { District (CBD) of } \\
\text { Melbourne. } \\
\text { Characterized by } \\
\text { very dense, high } \\
\text { buildings and a } \\
\text { relatively large } \\
\text { number of people } \\
\text { on the street. }\end{array}$ & 14965 & Walking \\
\hline 7 & $\begin{array}{l}\text { Industrial } \\
\text { Area }\end{array}$ & Altona & $\begin{array}{l}\text { Industrial Area } \\
\text { North of Altona; } \\
\text { Contains large one } \\
\text { to two storey } \\
\text { buildings used for } \\
\text { fabrication, } \\
\text { storage, } \\
\text { manufacturing, and } \\
\text { logistics; Area also } \\
\text { contains some } \\
\text { unused open space } \\
\text { and relatively wide } \\
\text { roads. } \\
\text { Transportation is } \\
\text { mainly done in cars } \\
\text { and trucks. }\end{array}$ & 915 & $\begin{array}{l}\text { Driving around } \\
\text { in a car in the } \\
\text { passenger seat. }\end{array}$ \\
\hline 8 & Beach & $\begin{array}{l}\text { South } \\
\text { Melbourne }\end{array}$ & $\begin{array}{l}\text { Beach; Area } \\
\text { contains almost no } \\
\text { buildings; Mainly } \\
\text { used for } \\
\text { recreational } \\
\text { activities; Next to } \\
\text { the sea. }\end{array}$ & 7050 & Walking \\
\hline 9 & $\begin{array}{l}\text { Suburban } \\
\text { Area } 1\end{array}$ & $\begin{array}{l}\text { Prahran and } \\
\text { Windsor }\end{array}$ & $\begin{array}{l}\text { Two residential } \\
\text { neighbourhoods in } \\
\text { the south of } \\
\text { Melbourne; } \\
\text { Buildings are } \\
\text { mainly one to two } \\
\text { storey buildings; } \\
\text { There is } \\
\text { commercial } \\
\text { activity along the } \\
\text { main roads; The } \\
\text { areas are } \\
\text { predominantly flat. }\end{array}$ & 7370 & $\begin{array}{l}\text { Riding a } \\
\text { bicycle }\end{array}$ \\
\hline 10 & $\begin{array}{l}\text { University } \\
\text { Campus } 2\end{array}$ & Hawthorne & $\begin{array}{l}\text { Swinburne } \\
\text { University campus. } \\
\text { A newer campus } \\
\text { than the one } \\
\text { studied in area } 4 . \\
\text { Buildings of } 3-4 \\
\text { storeys high, }\end{array}$ & 4286 & Walking \\
\hline
\end{tabular}




\begin{tabular}{|c|c|c|c|c|c|}
\hline & & & $\begin{array}{l}\text { mainly used for } \\
\text { academic } \\
\text { activities; The } \\
\text { main mode of } \\
\text { transportation in } \\
\text { this area is on foot. }\end{array}$ & & \\
\hline 11 & $\begin{array}{l}\text { Suburban } \\
\text { Area } 2\end{array}$ & Hawthorne & $\begin{array}{l}\text { First residential } \\
\text { neighbourhood in } \\
\text { Hawthorn, located } \\
\text { in the east of } \\
\text { Melbourne; This } \\
\text { area contains } \\
\text { mainly one- to } \\
\text { two-storey } \\
\text { residential } \\
\text { buildings; The area } \\
\text { is hilly. }\end{array}$ & 4286 & Walking \\
\hline 12 & $\begin{array}{l}\text { Suburban } \\
\text { Area } 3\end{array}$ & Hawthorne & $\begin{array}{l}\text { Second residential } \\
\text { neighbourhood in } \\
\text { Hawthorn, located } \\
\text { in the east of } \\
\text { Melbourne; This } \\
\text { area contains } \\
\text { mainly one- to } \\
\text { two-storey } \\
\text { residential } \\
\text { buildings; The area } \\
\text { is hilly. }\end{array}$ & 4286 & Walking \\
\hline 13 & $\begin{array}{l}\text { Suburban } \\
\text { Area } 4\end{array}$ & Werribee & $\begin{array}{l}\text { A residential } \\
\text { neighbourhood } \\
\text { located in the } \\
\text { outskirts of greater } \\
\text { Melbourne; This } \\
\text { area mainly } \\
\text { contains detached } \\
\text { one-storey } \\
\text { residential } \\
\text { buildings and has } \\
\text { relatively broad } \\
\text { streets in } \\
\text { comparison to the } \\
\text { other residential } \\
\text { buildings; The area } \\
\text { is flat. }\end{array}$ & 249 & Walking \\
\hline 14 & $\begin{array}{l}\text { Suburban } \\
\text { Area } 5\end{array}$ & Werribee & $\begin{array}{l}\text { A second } \\
\text { residential } \\
\text { neighbourhood } \\
\text { located in } \\
\text { Werribee. The } \\
\text { geographical } \\
\text { features of this } \\
\text { neighbourhood are } \\
\text { similar as area 13; } \\
\text { The neighbourhood } \\
\text { hosts inhabitants } \\
\text { with a higher } \\
\text { income than } \\
\text { neighbourhood } 13 \text {. }\end{array}$ & 249 & Walking \\
\hline
\end{tabular}




\begin{tabular}{|c|c|c|c|c|}
\hline 15 & $\begin{array}{l}\text { Suburban } \\
\text { area } 6\end{array}$ & Werribee & $\begin{array}{l}\text { The whole county } \\
\text { of Werribee, which } \\
\text { includes } \\
\text { residential, rural, } \\
\text { and commercial } \\
\text { areas is considered; } \\
\text { Transportation by } \\
\text { car is very } \\
\text { common in this } \\
\text { outer suburb of } \\
\text { Melbourne. }\end{array}$ & $\begin{array}{l}\text { Driving around } \\
\text { in a car in the } \\
\text { driver's seat }\end{array}$ \\
\hline $\begin{array}{l}\text { Mode of } \\
\text { Transportation }\end{array}$ & & & Characteristics & Activities \\
\hline Bicycle & & & $\begin{array}{l}\text { Transportation in } \\
\text { between the } \\
\text { measurements, } \\
\text { through the } \\
\text { different } \\
\text { neighbourhoods of } \\
\text { South Melbourne. }\end{array}$ & $\begin{array}{l}\text { Riding a } \\
\text { bicycle }\end{array}$ \\
\hline Train & & & $\begin{array}{l}\text { Transportation in } \\
\text { between Flinders } \\
\text { street station } \\
\text { (Melbourne's main } \\
\text { train station) and } \\
\text { either Prahran } \\
\text { station (Prahran), } \\
\text { Glenferrie station } \\
\text { (Hawthorne), and } \\
\text { Werribee station } \\
\text { (Werribee). }\end{array}$ & $\begin{array}{l}\text { Standing or } \\
\text { sitting down in } \\
\text { a train. }\end{array}$ \\
\hline Car & & & $\begin{array}{l}\text { Transportation } \\
\text { from Prahran to } \\
\text { Altona and back. }\end{array}$ & $\begin{array}{l}\text { Sitting in the } \\
\text { passenger seat } \\
\text { of the car. }\end{array}$ \\
\hline Tram & & & $\begin{array}{l}\text { Transportation in } \\
\text { between Flinders } \\
\text { street station and } \\
\text { the Alfred } \\
\text { Hospital. }\end{array}$ & $\begin{array}{l}\text { Standing or } \\
\text { sitting down in } \\
\text { a tram. }\end{array}$ \\
\hline Places of interest & & County & $\begin{array}{l}\text { Study sites and } \\
\text { characteristics }\end{array}$ & Activities \\
\hline Tram station & & South Yarra & $\begin{array}{l}\text { Domain } \\
\text { Interchange, } \\
\text { Melbourne; a } \\
\text { typical tram station } \\
\text { with } 15-20 \text { people } \\
\text { around, business } \\
\text { and public } \\
\text { buildings nearby }\end{array}$ & $\begin{array}{l}\text { Standing and } \\
\text { walking } \\
\text { around the } \\
\text { tram waiting } \\
\text { points }\end{array}$ \\
\hline Tram station & & $\begin{array}{l}\text { Melbourne } \\
\text { CBD }\end{array}$ & $\begin{array}{l}\text { Flinder's street } \\
\text { tram station, } \\
\text { Melbourne; One } \\
\text { of Melbourne's } \\
\text { main tram stations } \\
\text { with many people } \\
\text { around. }\end{array}$ & $\begin{array}{l}\text { Standing and } \\
\text { walking } \\
\text { around the } \\
\text { tram waiting } \\
\text { points }\end{array}$ \\
\hline
\end{tabular}




\begin{tabular}{|c|c|c|c|}
\hline Tram station & South Yarra & $\begin{array}{l}\text { The Alfred tram } \\
\text { station, Melbourne; } \\
\text { Tram station in } \\
\text { front of the Alfred } \\
\text { hospital in South } \\
\text { Yarra, with few } \\
\text { people (1-5) } \\
\text { around. }\end{array}$ & $\begin{array}{l}\text { Standing and } \\
\text { walking } \\
\text { around the } \\
\text { tram waiting } \\
\text { points }\end{array}$ \\
\hline Children's playground & $\begin{array}{l}\text { South } \\
\text { Melbourne }\end{array}$ & $\begin{array}{l}\text { A children's } \\
\text { playground located } \\
\text { in Albert Park. }\end{array}$ & $\begin{array}{l}\text { Sitting near the } \\
\text { playground. }\end{array}$ \\
\hline Train station & $\begin{array}{l}\text { Melbourne } \\
\text { CBD }\end{array}$ & $\begin{array}{l}\text { Flinders street train } \\
\text { station. } \\
\text { Melbourne's main } \\
\text { train station. Very } \\
\text { busy with at any } \\
\text { moment more than } \\
\text { a } 1000 \text { people } \\
\text { around. }\end{array}$ & $\begin{array}{l}\text { Standing and } \\
\text { walking } \\
\text { around the } \\
\text { main hall of } \\
\text { the station. } \\
\text { Standing and } \\
\text { walking } \\
\text { around on the } \\
\text { platform. }\end{array}$ \\
\hline Train station & Prahran & $\begin{array}{l}\text { Prahran train } \\
\text { station. Small train } \\
\text { station with two } \\
\text { platforms. Busy in } \\
\text { rush hours, but } \\
\text { with few people (< } \\
\text { 30) around on } \\
\text { other times. }\end{array}$ & $\begin{array}{l}\text { Standing and } \\
\text { walking } \\
\text { around on the } \\
\text { platform. }\end{array}$ \\
\hline Train station & Hawthorne & $\begin{array}{l}\text { Glenferrie train } \\
\text { station. Medium } \\
\text { sides train station } \\
\text { with four } \\
\text { platforms. Very } \\
\text { busy (> } 100 \\
\text { persons) in rush } \\
\text { hours and always > } \\
30 \text { people on the } \\
\text { platforms. }\end{array}$ & $\begin{array}{l}\text { Standing and } \\
\text { walking } \\
\text { around on the } \\
\text { platform. }\end{array}$ \\
\hline Subway station & $\begin{array}{l}\text { Melbourne } \\
\text { CBD }\end{array}$ & $\begin{array}{l}\text { Melbourne Central; } \\
\text { One of } \\
\text { Melbourne's } \\
\text { busiest } \\
\text { underground } \\
\text { stations; located on } \\
\text { the city loop, a } \\
\text { circular metro line } \\
\text { underneath } \\
\text { Melbourne's CBD. }\end{array}$ & $\begin{array}{l}\text { Standing and } \\
\text { walking } \\
\text { around on the } \\
\text { platform. }\end{array}$ \\
\hline Shopping Centre & $\begin{array}{l}\text { Melbourne } \\
\text { CBD }\end{array}$ & $\begin{array}{l}\text { Melbourne Central; } \\
\text { Multi-storey } \\
\text { shopping centre on } \\
\text { top of the } \\
\text { underground } \\
\text { station. }\end{array}$ & $\begin{array}{l}\text { Walking in } \\
\text { between the } \\
\text { stores. }\end{array}$ \\
\hline
\end{tabular}

Fig. A.1: Overview of the 15 studied microenvironments (source: Google Earth, Alphabet inc., Mountain View, CA, USA). 


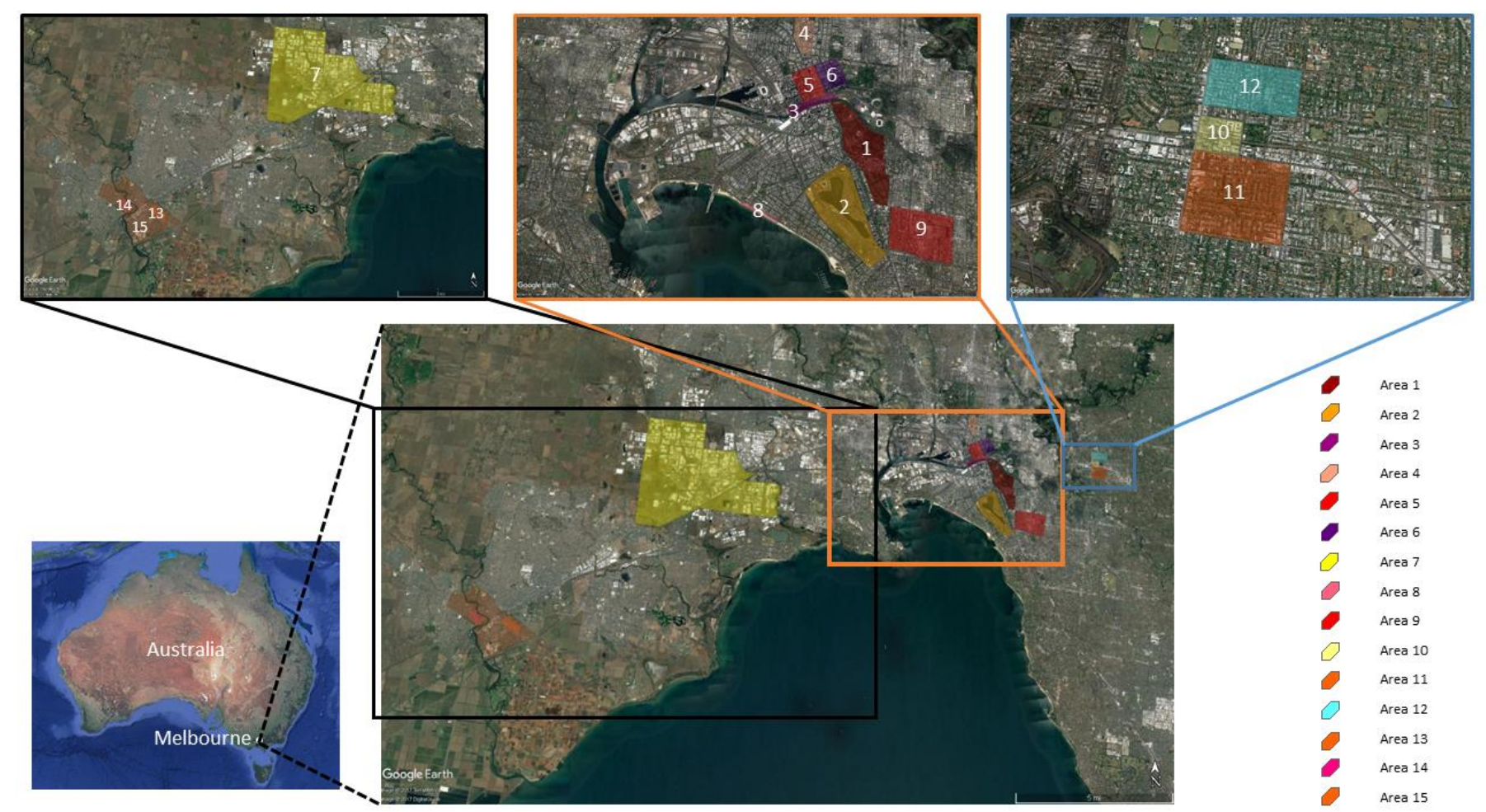

\section{Appendix B}

\section{On-body Calibration Procedure}

The goal of the on-body calibration was to determine a relationship between the RF power $\left(\mathrm{P}_{\mathrm{r}}\right)$ received on the nodes that were placed in the PDE-Helmet (see Fig. 1 (c)) and the incident Electric Field strength $\left(\mathrm{E}_{\mathrm{rms}}\right)$. Both quantities are related through a quantity named antenna aperture (AA) (Balanis, 1986):

$$
A A=\frac{P_{r}}{S}=\frac{377 \times P_{r}}{E_{\text {inc }}{ }^{2}}, \quad \quad \text { Eq. } 1
$$

Or alternatively:

$$
E_{\text {inc }}=\sqrt{\frac{377 \times P_{r}}{A A}}, \quad \text { Eq. } 2
$$

During the calibration procedure, we used three steps in order to determine AA. i) Measurement of freespace incident fields. ii) Measurements of received RF power on the PDE-Helmet as function of angle of incidence. iii) Calculation of antenna aperture of the PDE-Helmet under far-field exposure to RFEMFs. This calibration procedure is based on the one presented in Thielens et al. (2016).

During the first two steps, an incident electric field ( $E_{\text {inc }}$ ) was generated using a linearly polarized horn antenna on one side of an anechoic chamber, which emitted continuous wave with an input power of $10 \mathrm{dBm}$ at $942.5 \mathrm{MHz}$. 
In the first step, $E_{\text {inc }}$ was measured using a NBM-550 broadband field meter (Narda, Hauppauge, NY, USA) at the other side of the anechoic chamber. The E-field was measured along a vertical line (orthogonal to the floor) from $0.38 \mathrm{~m}$ to $2.01 \mathrm{~m}$, which represents an averaging over the full body height. $E_{\text {inc }}$ values were registered for two orthogonal polarizations of the incident field: Vertical (orthogonal to the floor) and Horizontal (parallel to the floor).

In the second step, the researcher wearing the PDE-Helmet stood in the anechoic chamber at the same location where the $\mathrm{E}_{\text {inc }}$ in the first step was measured. The PDE-Helmet contained four stub antennas tuned to the $900 \mathrm{DL}$ band $(925-960 \mathrm{MHz})$ placed on the locations shown in Fig. 1 (b) \& (c). The used antennas were linearly polarized. Ideally, one would like to measure two orthogonal linear polarizations at each side of the helmet. However, such a realization was not possible in the available space in the helmet and depolarization of the antennas is expected near the body (Aminzadeh et al., 2016). The antennas were connected, using a shielded SubMiniature version A connector with the same RF nodes used in Thielens et al. (2016), which contain a filter tuned to the 900 DL band In a real exposure situation, incident RF-EMFs can have any polarization and can come from any direction. In order to include this diversity in our calibration, the researcher was rotated over $360^{\circ}$ in azimuthal while being exposed to a constant electric field $\left(E_{\text {inc }}\right)$. This rotation was performed for both $\mathrm{V}$ and $\mathrm{H}$ polarization. During the rotation, the nodes recorded received powers $\left(P_{r}\right)$ on the antennas. These powers depend on the angle of incidence and the incident polarization (Thielens et al. 2016), which implies that AA has a distribution. The spread of this distribution determines the measurement uncertainty $\mathrm{E}_{\mathrm{inc}}$, see Eq. 2.

In the third step, we determined the distribution of AA under the assumption that any polarization and angle of incidence is equally likely to occur. The distribution of $A A$ was characterized by its median value $\left[p_{50}(A A)\right]$ and $68 \%$ confidence interval $C I_{68}$ (with $p_{16}(A A)$ and $p_{84}(A A)$, the $16^{\text {th }}$ and $84^{\text {th }}$ percentile of the distribution of $A A$ ):

$$
C I_{68}=\frac{p_{84}(A A)}{p_{16}(A A)}, \quad \text { Eq. } 3
$$

A perfectly isotropic antenna (constant $\mathrm{AA}$ ) will have a $C I_{68}=1$, so a value close to one is desirable.

During measurements, $\hat{E}_{\text {inc }}$ can be estimated from the measured received powers $P_{r}$ by the PDE-Helmet using this antenna aperture. In this study, we estimated the incident field strength $\left(\widehat{E}_{\text {inc }}\right)$, using the median $A A\left[p_{50}(A A)\right]$ :

$$
\widehat{E}_{\text {inc }}=\sqrt{\frac{377 \times P_{r}}{p_{50}(A A)}}, \quad \text { Eq.4 }
$$

Previous studies have shown that the distribution of the AA of the ensemble of antennas distributed on the body of a subject has a smaller $\mathrm{CI}_{68}$ than that of a single antenna on the body (Thielens et al. 2013). Consequently the estimation of $\hat{E}_{\text {inc }}$ can happen with less uncertainty. Figure B.1 shows the $\mathrm{CI}_{68}$ of the four individual nodes in the helmet and of the geometric average over all four nodes. It is clear that the $\mathrm{CI}_{68}$ on the AA of the PDE-Helmet is smaller for the average over four nodes, compared to the individual nodes. 


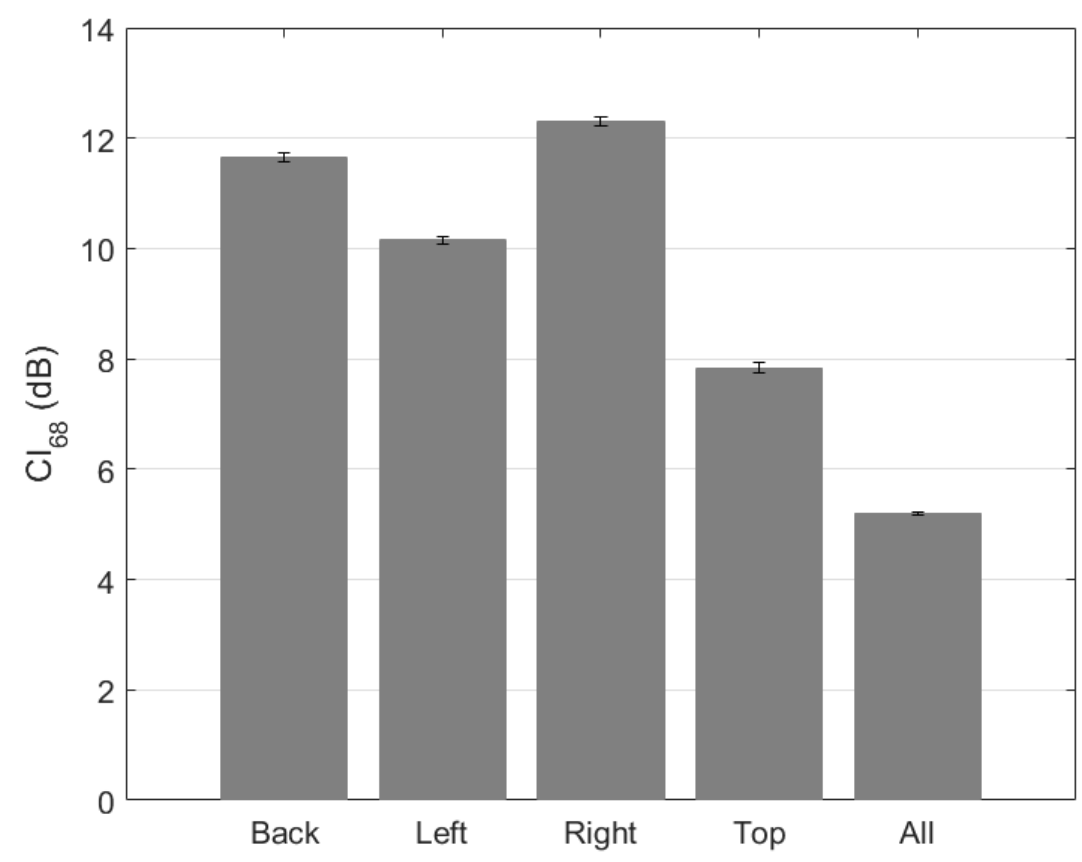

Figure B.1: 68\% confidence interval on the incident electric field strength for the four individual nodes placed in the PDE-Helmet and the geometric average over the four nodes.

The median value of the AA averaged over the four nodes is $1.844 \pm 0.02 \mathrm{~cm}^{2}$ with a $\mathrm{CI}_{68}$ of $4.9 \pm$ $0.05 \mathrm{~dB}$. The lower detection limits of the four nodes is $-72 \mathrm{dBm}\left(6.3 \times 10^{-8} \mathrm{~mW}\right)$, which implies a lower LOD of $0.0113 \mathrm{~V} / \mathrm{m}$. The upper detection limit in terms of power is is $8 \mathrm{dBm}$, which corresponds to $113 \mathrm{~V} / \mathrm{m}$. 


\section{Appendix C}

Table C.1: Proportion of non-detects below the lower limit of detection in each frequency band of the ExpoM-RF per microenvironment.

\begin{tabular}{|c|c|c|c|c|c|c|c|c|c|c|c|c|c|c|c|c|}
\hline Microenvironment & 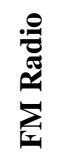 & 草 & $\stackrel{2}{8}$ & $\stackrel{ఠ}{\S}$ & 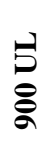 & $\stackrel{2}{8}$ & $\begin{array}{l}\rho \\
\stackrel{\rho}{8} \\
\stackrel{\infty}{8}\end{array}$ & $\begin{array}{l}\overrightarrow{0} \\
\stackrel{\infty}{8}\end{array}$ & $\underset{\underline{0}}{\underline{0}}$ & $\underset{8}{\stackrel{5}{\sigma}}$ & $\frac{\bar{\theta}}{\hat{\theta}}$ & 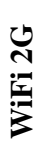 & $\begin{array}{l}5 \\
\stackrel{5}{0} \\
\stackrel{0}{0}\end{array}$ & 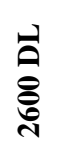 & 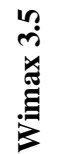 & $\begin{array}{l}0 \\
10 \\
1 \\
1\end{array}$ \\
\hline 1, park close to CBD 1 & 33 & 0 & 5 & 0 & 0 & 0 & 88 & 0 & 14 & 72 & 0 & 25 & 92 & 4 & 96 & 80 \\
\hline 2, park close to CBD 2 & 77 & 0 & 1 & 0 & 0 & 0 & 85 & 0 & 1 & 97 & 0 & 28 & 92 & 0 & 92 & 63 \\
\hline $3, \mathrm{CBD} 1$ & 21 & 0 & 1 & 0 & 0 & 0 & 48 & 0 & 0 & 97 & 0 & 1 & 71 & 0 & 71 & 22 \\
\hline 4, University Campus 1 & 35 & 1 & 6 & 2 & 1 & 0 & 75 & 1 & 5 & 87 & 0 & 5 & 95 & 8 & 89 & 67 \\
\hline $5, \mathrm{CBD} 2$ & 5 & 0 & 1 & 2 & 0 & 0 & 45 & 0 & 0 & 95 & 0 & 0 & 66 & 0 & 76 & 25 \\
\hline 6, CBD 3 & 5 & 0 & 0 & 0 & 0 & 0 & 60 & 0 & 0 & 98 & 0 & 0 & 74 & 0 & 82 & 29 \\
\hline 7, Industrial Area & 100 & 37 & 47 & 94 & 22 & 0 & 100 & 7 & 69 & 100 & 8 & 19 & 64 & 93 & 100 & 100 \\
\hline 8 , Beach & 98 & 4 & 22 & 19 & 0 & 0 & 98 & 0 & 0 & 100 & 0 & 41 & 100 & 6 & 100 & 95 \\
\hline 9, Suburban Area 1 & 93 & 4 & 26 & 42 & 2 & 0 & 90 & 0 & 36 & 70 & 1 & 11 & 99 & 53 & 97 & 88 \\
\hline 10, University Campus 2 & 90 & 1 & 4 & 16 & 0 & 0 & 88 & 0 & 3 & 99 & 0 & 4 & 98 & 40 & 96 & 65 \\
\hline 11, Suburban Area 2 & 96 & 8 & 32 & 57 & 0 & 0 & 96 & 0 & 53 & 100 & 1 & 34 & 100 & 87 & 98 & 94 \\
\hline 12, Suburban Area 3 & 99 & 3 & 15 & 22 & 0 & 0 & 97 & 0 & 9 & 99 & 0 & 26 & 100 & 64 & 98 & 92 \\
\hline 13, Suburban Area 4 & 100 & 23 & 77 & 99 & 12 & 0 & 100 & 20 & 86 & 55 & 10 & 43 & 100 & 74 & 100 & 100 \\
\hline 14, Suburban Area 5 & 100 & 30 & 64 & 100 & 1 & 0 & 99 & 0 & 32 & 88 & 0 & 33 & 100 & 100 & 100 & 100 \\
\hline 15, Suburban Area 6 & 100 & 31 & 57 & 86 & 19 & 0 & 99 & 20 & 54 & 81 & 5 & 46 & 100 & 71 & 100 & 99 \\
\hline \multicolumn{17}{|l|}{ Mode of Transport } \\
\hline Train & 90 & 12 & 27 & 30 & 5 & 0 & 21 & 5 & 25 & 27 & 6 & 12 & 86 & 63 & 99 & 90 \\
\hline Bus & 81 & 8 & 19 & 7 & 0 & 0 & 25 & 0 & 38 & 32 & 0 & 6 & 90 & 35 & 100 & 95 \\
\hline Tram & 51 & 0 & 12 & 16 & 2 & 0 & 36 & 1 & 18 & 57 & 0 & 2 & 61 & 6 & 96 & 76 \\
\hline Bike & 65 & 0 & 4 & 3 & 0 & 0 & 78 & 0 & 4 & 90 & 0 & 11 & 93 & 14 & 92 & 62 \\
\hline Car & 98 & 11 & 36 & 52 & 5 & 0 & 99 & 5 & 35 & 72 & 2 & 21 & 72 & 41 & 100 & 96 \\
\hline Walking & 44 & 5 & 9 & 24 & 1 & 0 & 73 & 1 & 11 & 95 & 0 & 9 & 86 & 23 & 88 & 64 \\
\hline \multicolumn{17}{|l|}{ Places of interest } \\
\hline Melbourne Central & 59 & 15 & 39 & 23 & 1 & 0 & 34 & 3 & 5 & 83 & 2 & 0 & 33 & 4 & 99 & 21 \\
\hline Prahran Station & 100 & 0 & 41 & 5 & 0 & 0 & 96 & 0 & 2 & 97 & 0 & 5 & 100 & 100 & 100 & 100 \\
\hline Flinders St. & 47 & 0 & 13 & 1 & 0 & 0 & 28 & 0 & 1 & 60 & 0 & 1 & 54 & 1 & 94 & 60 \\
\hline Glenferrie & 100 & 0 & 0 & 11 & 0 & 0 & 96 & 0 & 7 & 93 & 0 & 1 & 86 & 7 & 100 & 94 \\
\hline North Melb. Station & 100 & 4 & 4 & 3 & 0 & 0 & 14 & 9 & 16 & 6 & 5 & 1 & 85 & 16 & 100 & 87 \\
\hline Playground & 100 & 0 & 0 & 0 & 0 & 0 & 94 & 0 & 0 & 100 & 0 & 33 & 89 & 1 & 93 & 45 \\
\hline All Measurements & 74 & 19 & 39 & 37 & 7 & $\mathbf{0}$ & 74 & 6 & 29 & 89 & 11 & 16 & 92 & 42 & 94 & 81 \\
\hline
\end{tabular}

